\title{
Article
}

\section{Cranial morphology of the middle Permian pareiasaur Nochelesaurus alexanderi from the Karoo Basin of South Africa}

\section{Marc J. VAN DEN BRANDT ${ }^{1 *} \bullet$, Bruce S. RUBIDGE ${ }^{1}$, Julien BENOIT ${ }^{1}$ and Fernando ABDALA ${ }^{2}$}

\author{
${ }^{1}$ Evolutionary Studies Institute and School of Geosciences, University of the Witwatersrand, Johannesburg, PO WITS \\ 2050, South Africa. \\ ${ }^{2}$ Unidad Ejecutora Lillo, CONICET-Fundación Miguel Lillo, Miguel Lillo 251, Tucumán, Argentina. \\ *Corresponding author. Email: marcvandenbrandt@gmail.com
}

\begin{abstract}
Pareiasaurs were globally distributed, abundant, herbivorous parareptiles with the basal-most members found only in the mid-Permian of South Africa. These basal forms form a monophyletic group and were locally abundant and became extinct at the top of the Tapinocephalus Assemblage Zone at the end of the Guadalupian. Four species of basal pareiasaurs are currently recognised: Bradysaurus baini, B. seeleyi, Embrithosaurus schwarzi and Nochelesaurus alexanderi, but they are all poorly understood and there remains historic uncertainty as to their validity. In this paper, our second contribution designed to improve understanding of the basal group, we present the first detailed cranial description and updated diagnosis for Nochelesaurus alexanderi and demonstrate that it is a distinct taxon based on one cranial autapomorphy, a large transversely wide postparietal, and a combination of cranial characters. Within the local group of mid-Permian pareiasaurs, we recognise new dental features of Nochelesaurus alexanderi: non-symmetrical marginal cusp arrangements on upper and lower teeth resulting from an extra basal mesial cusp; an incipient horizontal cingulum on lower jaw teeth, sometimes with one or two tiny medial cingular cusps; and up to ten marginal cusps. Our study demonstrates that tooth morphology and orientation, cranial ornamentation, morphology of the cheek bosses, shape of the postfrontal and postparietal, and morphology of the distal paroccipital process of the opisthotic are the most useful to identify South African mid-Permian pareiasaurs.
\end{abstract}

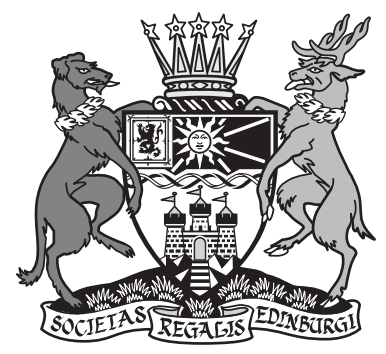

KEY WORDS: Capitanian, Guadalupian, Parareptilia, Pareiasauria, Permian, Tapinocephalus Assemblage Zone.

Pareiasaurs were a group of relatively abundant armoured, herbivorous parareptiles with a worldwide distribution that flourished in the middle to late Permian (Boonstra 1969; Lee 1993, 1994, $1997 \mathrm{a}, \mathrm{b})$. Eleven of the currently recognised 24 species are found in South Africa, where the pareiasaurs are represented in two distinct stratigraphic ranges: the mid-Permian Tapinocephalus Assemblage Zone (AZ) and the late Permian Tropidostoma, Cistecephalus and Daptocephalus AZs (Boonstra 1932; Kitching 1995; Smith \& Keyser 1995a, b, c; Lee 1997a). All phylogenetic analyses indicate that the pareiasaurs from the Tapinocephalus AZ of South Africa are the most basal genera of the group (Lee 1997a, b; Jalil \& Janvier 2005; Tsuji 2010; Tsuji et al. 2013; Turner et al. 2015; Benton 2016; Liu \& Bever 2018; Van den Brandt et al. 2020). These basal taxa are therefore important as they form a baseline from which to investigate the origin, diversification and subsequent distribution of the group. After a long history of taxonomic confusion and inflated numbers of taxa, four species of basal pareiasaurs from the Tapinocephalus AZ are currently recognised since the seminal taxonomic review of Lee (1994, 1997a): Bradysaurus baini, B. seeleyi, Embrithosaurus schwarzi and Nochelesaurus alexanderi.
However, despite Lee's updated diagnoses, these pareiasaurs remain poorly understood.

Haughton \& Boonstra (1929) erected the genus Nochelesaurus, based on crania alone, recognising two, briefly diagnosed species; $N$. strubeni and $N$. alexanderi. Boonstra (1934) retained both species, expanded the cranial diagnoses at a generic and species level, and produced rough cranial illustrations of the holotypes of both species in all major views. Subsequent contributions reproduced Boonstra's (1934) rough cranial illustrations of $N$. alexanderi (e.g., Kuhn 1969) and these are still the only published cranial illustrations of this taxon.

Nochelesaurus strubeni was recognised as Bradysaurus strubeni by Broom (1935) and Boonstra (1969), as Embrithosaurus strubeni by Kuhn (1969), and was declared indeterminate by Lee (1994, 1997a). Nochelesaurus alexanderi was recognised as Embrithosaurus alexanderi by Kuhn (1969) but as N. alexanderi by Lee $(1994,1997$ a). Detailed cranial descriptions for $N$. alexanderi have never been produced and only brief comparative diagnoses have been provided in taxonomic reviews (Haughton \& Boonstra 1929; Boonstra 1934; Kuhn 1969; Lee 1994, 1997a). 


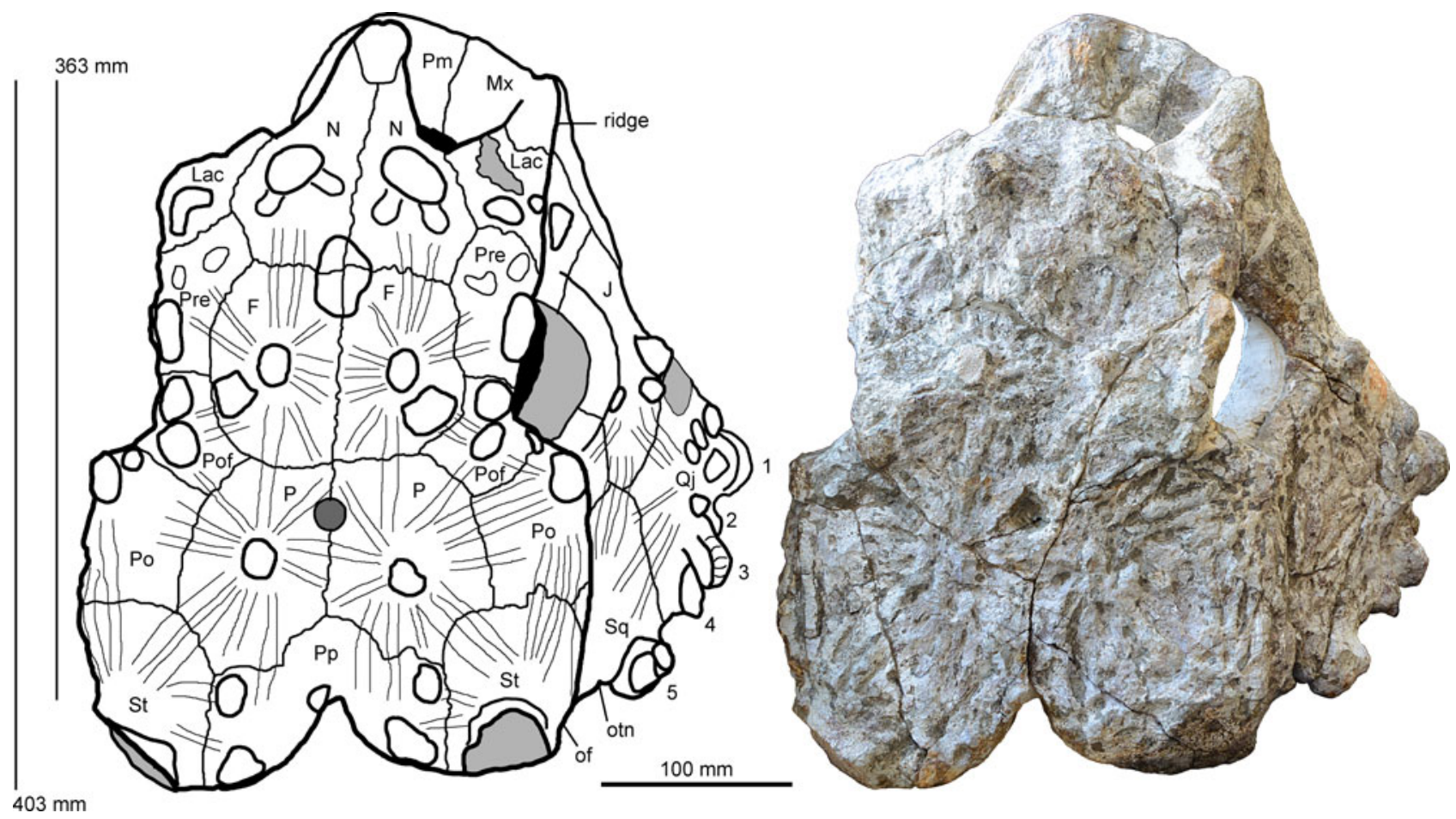

Figure 1 Photograph and interpretive drawing of the skull of the holotype of Nochelesaurus alexanderi (SAM-PK-6239), in dorsal view. Skull length of $403 \mathrm{~mm}$ : posterior edge of the dorsal premaxilla to the posterior edge of the midline occipital flange, and $363 \mathrm{~mm}$ : posterior edge of the dorsal premaxilla to the posterior edge of the left-most corner of the occipital flange. Abbreviations: $\mathrm{F}=$ frontal; $\mathrm{J}=$ jugal; $\mathrm{Lac}=$ lacrimal; $\mathrm{Mx}=\mathrm{maxilla} ; \mathrm{N}=$ nasal; of $=$ occipital flange; otn = otic notch; $\mathrm{P}=$ parietal; $\mathrm{Pm}=$ premaxilla; $\mathrm{Po}=$ postorbital; $\mathrm{Pof}=$ postfrontal; $\mathrm{Pp}=$ postparietal; $\mathrm{Pre}=$ prefrontal; $\mathrm{Qj}=$ quadratojugal; $\mathrm{Sq}=$ squamosal; $\mathrm{St}=$ supratemporal.

In the first in a series of papers designed to update the anatomy, taxonomy, phylogeny and stratigraphic ranges of basal South African pareiasaurs, Van den Brandt et al. (2020) produced an updated cranial description and diagnosis for Embrithosaurus schwarzi. We included a new phylogenetic analysis in which we recovered the basal South African taxa as a monophyletic group for the first time, which we named the Bradysauria. Van den Brandt et al. (2020) explained in detail the motivations for the project, and the current level of knowledge, and the unique challenges of studying the pareiasaurs from the Tapinocephalus AZ. To clearly diagnose and distinguish $N$. alexanderi from the other co-occurring pareiasaurid species of the Tapinocephalus AZ, a new and updated modern cranial description is required, including updated diagnoses and cranial illustrations. This contribution forms the second part of a series of papers designed to update the taxonomy of the basal midPermian South African pareiasaurs from the Tapinocephalus AZ.

\section{Material and methods}

\subsection{Preparation}

The skull and postcranium of the holotype of Nochelesaurus alexanderi were mechanically prepared using hammer and chisel in the 1920s, with better than average results for this period. The cranial ornamentation is distinct and mostly undamaged, and only minor deposits of matrix remained. Additional preparation using compressed air-driven air scribes with a tungsten carbide tip was performed by Pepson Mukanela of the Evolutionary Studies Institute (ESI) at the University of the Witwatersrand, Johannesburg, in 2017 , to expose the palatal flanges of the premaxilla and maxilla, the sphenethmoid bone on the inner skull surface, the lateral walls of the braincase, the ventral surface of the pterygoid fragment, the lower jaw, and selected upper and lower marginal dentition. SAM-PK-6238 had been overprepared historically, smoothing over the external surface. The ventral surface of the palate was partially prepared by Johann van den Berg at the Iziko South African Museum in Cape Town in 2017 to reveal the small palatal teeth; however, much obscuring matrix remains. Specimens SAM-PK-6239A and CGP JA 109 were already well prepared.

\subsection{Suture identification}

Pareiasaurian cranial sutures are typically obscured by their ornamentation (Seeley 1888, 1892; Broom 1903; Watson 1914). However, unusual for a large adult pareisaur skull from the Tapinocephalus AZ, the cranial sutures of the Nochelesaurus holotype are easily identifiable as dark grey, matrix filled, interdigitating lines. On the inner surface of the skull, sutures are also apparent and confirm external sutural contacts. External and internal cranial sutures are also readily identifiable on referred specimens SAM-PK-6238 and SAM-PK-6239A.

\subsection{Key to interpretive drawings}

Sutures drawn in solid lines on the figures have been positively identified; those in dotted lines on external cranial surfaces are perpendicular extrapolations from internal surface sutures; dotted lines on the braincase, palate and lower jaw represent our interpretation taking typical mid-Permian pareiasaurian anatomy into account. Light grey indicates sides of bones or bone breaks, dark grey indicates foramen or fenestra, black indicates deep cavities such as orbits. Numbers indicate marginal cheek bosses; teeth positions counting back from the front; or tooth cusps. Cranial bosses are in bold line thickness, rugose ridges are in regular line thickness.

\subsection{Institutional abbreviations}

BP, Evolutionary Studies Institute, University of the Witwatersrand, Johannesburg (formerly the Bernard Price Institute for Palaeontological Research); CGP, Council for Geosciences, 

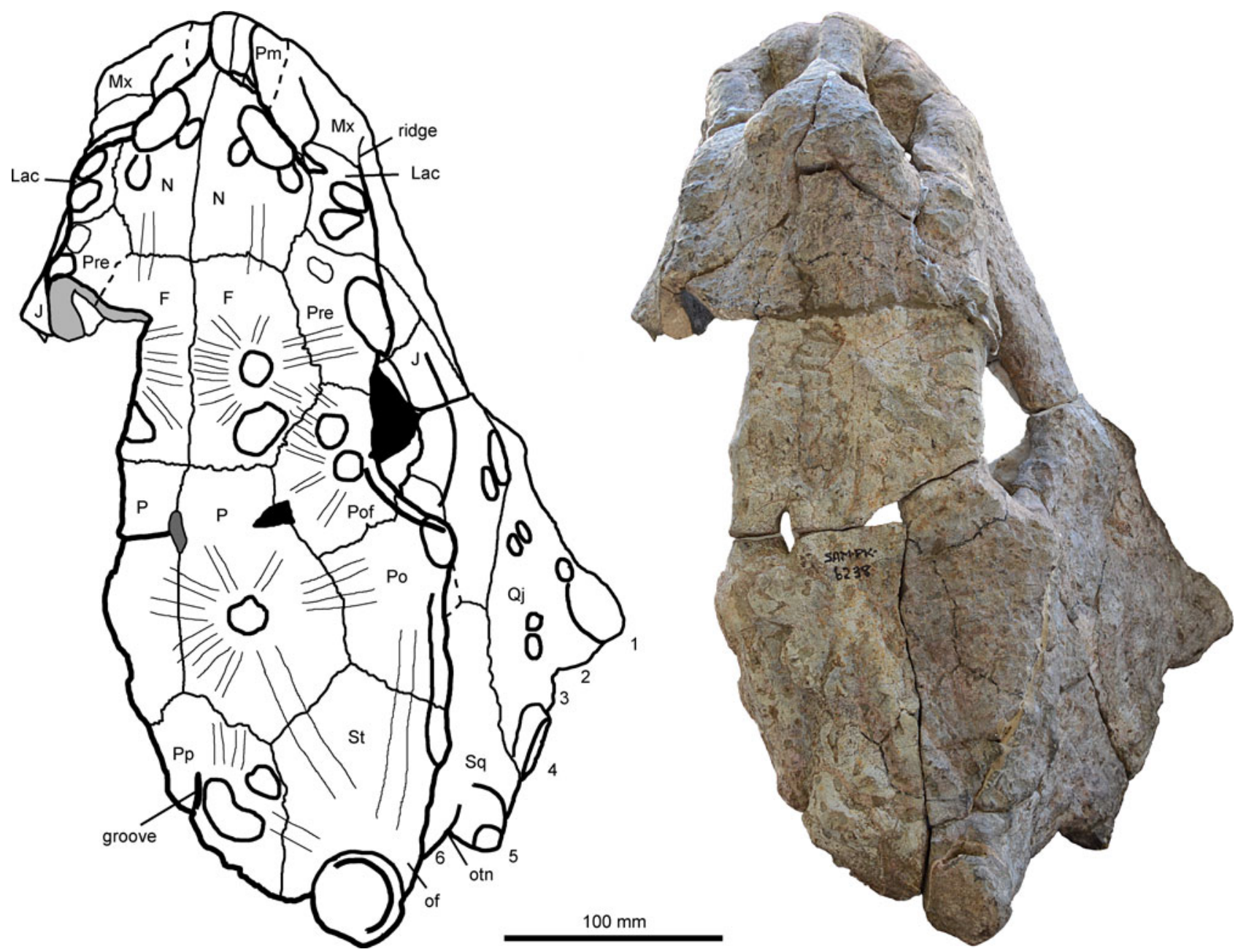

Figure 2 Photograph and interpretive drawing of the skull of a specimen of Nochelesaurus alexanderi (SAM-PK-6238, holotype of Dolichopareia angusta) in dorsal view. Abbreviations: $\mathrm{F}=$ frontal; $\mathrm{J}=$ jugal; Lac = lacrimal; $\mathrm{Mx}=$ maxilla; $\mathrm{N}=$ nasal; of $=$ occipital flange; otn = otic notch; $\mathrm{P}=$ parietal; $\mathrm{Pm}=$ premaxilla; $\mathrm{Po}=$ postorbital; $\mathrm{Pof}=$ postfrontal; $\mathrm{Pp}=$ postparietal; $\mathrm{Pre}=$ prefrontal; $\mathrm{Qj}$ = quadratojugal; $\mathrm{Sq}=$ squamosal; $\mathrm{St}=$ supratemporal .

Pretoria; FMNH, Field Museum of Natural History, Chicago; NHMUK, Natural History Museum, London; PIN, Paleontological Institute of the Russian Academy of Sciences, Moscow; SAM, Iziko South African Museum, Cape Town; UMZC, University Museum of Zoology, Cambridge.

\section{Systematic palaeontology}

\section{Class Reptilia Laurenti, 1768}

Order Parareptilia Olson, 1947

Suborder Pareiasauria Seeley, 1888

Family Pareiasauridae Cope, 1896

Genus Nochelesaurus Haughton \& Boonstra, 1929

(Figs 1-15)

\subsection{Type species}

Nochelesaurus alexanderi Haughton \& Boonstra, 1929 (SAM-PK-6239).

This specimen comprises the dorsal and right side of the skull and a partial right lower jaw, partial braincase and partial palate. Postcranial material comprises a partial right scapulocoracoid, cleithrum and clavicle, partial interclavicle, left humerus, seven articulated osteoderms, complete right femur and tibia, fibula fragment, astragalocalcaneum and about a dozen unnumbered unidentified fragments.

\subsection{Referred material}

CGP JA 109, partial skull and lower jaw; SAM-PK-6238 (holotype of Dolichopareia angusta, Haughton \& Boonstra, 1929), partial skull and lower jaw, partial shoulder girdle, both humeri, right radius and ulna, right fibula, second to sixteenth vertebrae and rib fragments; SAM-PK-6239A, large right cheek cranial fragment.

\subsection{Comparative material}

Comparative material studied includes NHMUK PV R1971, holotype skull and lower jaw of Bradysaurus baini; NHMUK PV R1970, snout and partial cranium of B. baini, SAMPK-5002, skull and lower jaw of B. baini; CGP/1/2269, juvenile skull and articulated anterior third of the postcranium of B. baini; SAM-PK-5624, very complete, articulated, mounted Bradysaurus skull and skeleton; NHMUK PV OR49426, holotype skull and lower jaw of Bradysaurus seeleyi; SAMPK-8034, holotype skull and lower jaw of Embrithosaurus schwarzi; NHMUK PV R7782, partial skull and lower jaw of E. schwarzi; CGP CBT 112, skull and occluded lower jaw of a large specimen of E. schwarzi; FMNH UR 2755, maxilla and partial lower jaw, partial pectoral girdle, several vertebrae, partial fore and hind limbs, and partial pelvis of a Nochelesaurus alexanderi; PIN 2212/2, holotype skull and lower jaw of Deltavjatia rossicus; PIN 2212/2, juvenile skull of D. rossicus; PIN 2212/ 6, juvenile skull and lower jaw of D. rossicus; UMZC T1321, skull and complete skeleton of D. rossicus; PIN 2005/1883, adult skull lacking lower jaw of Scutosaurus karpinski; PIN 

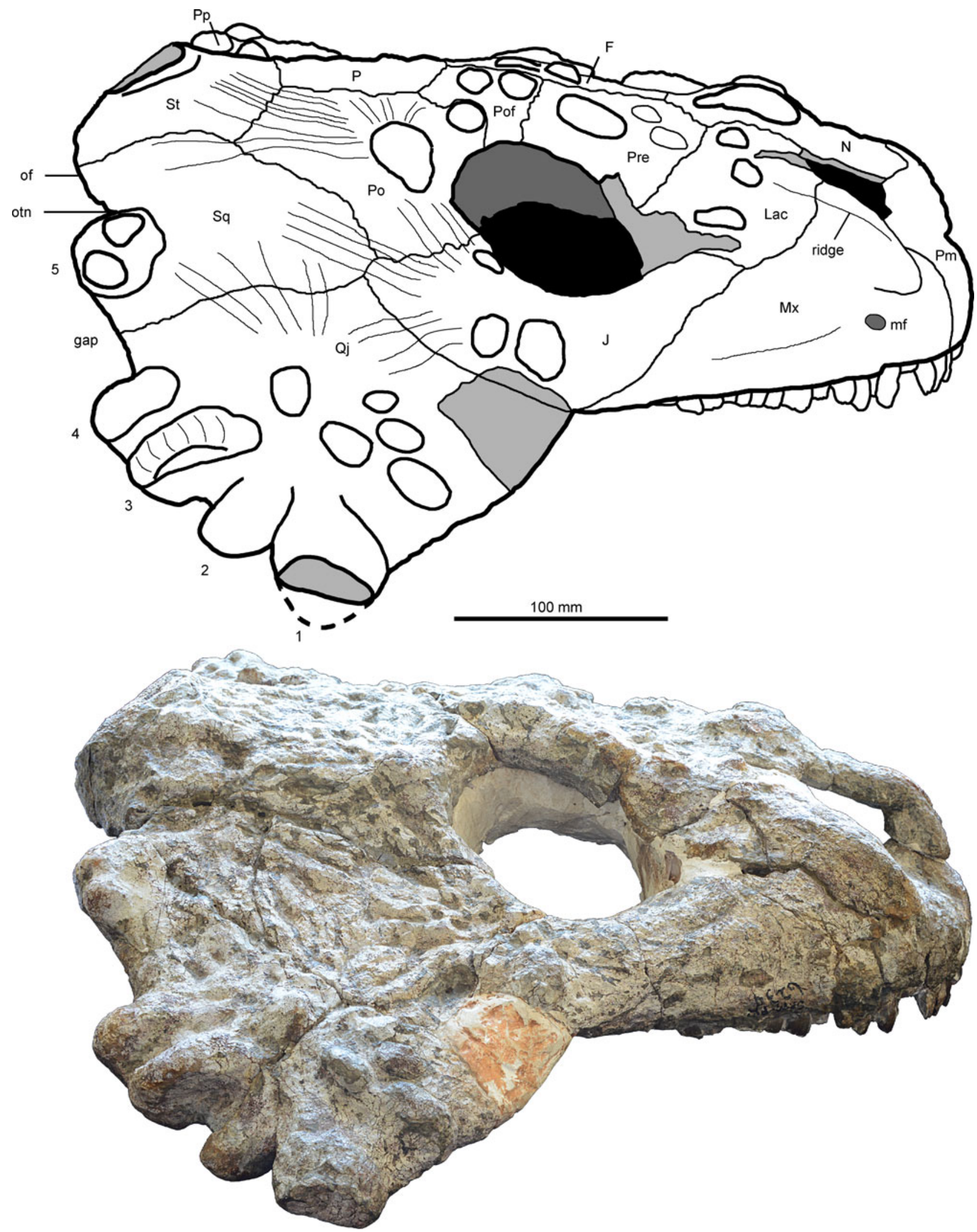

Figure 3 Photograph and interpretive drawing of the skull of the holotype of Nochelesaurus alexanderi (SAM-PK-6239) in right lateral view. Abbreviations: $\mathrm{F}=$ frontal; $\mathrm{J}=$ jugal; $\mathrm{Lac}=$ lacrimal; $\mathrm{mf}=$ maxillary foramen; $\mathrm{Mx}=$ maxilla; $\mathrm{N}=$ nasal; of = occipital flange; otn = otic notch; $\mathrm{P}=$ parietal; $\mathrm{Pm}=$ premaxilla; $\mathrm{Po}=$ postorbital; $\mathrm{Pof}=$ postfrontal; $\mathrm{Pp}=$ postparietal; $\mathrm{Pre}=$ prefrontal; $\mathrm{Qj}=$ quadratojugal; $\mathrm{Sq}=$ squamosal; $\mathrm{St}=$ supratemporal .

2005/1880, skull lacking lower jaw of $S$. karpinski; PIN 2005/1536, skull with lower jaw of $S$. karpinski; BP/1/3653, complete skull and lower jaw of Pareiasuchus nasicornis; PIN 4546/18, holotype quadratojugal of Obirkovia gladiator; SAM-PK-K11638, skull and lower jaw.

\subsection{Locality, stratigraphy and age}

Specimen SAM-PK-6239 was collected in 1923 from the farm Boesmanskop (Bushmans Kop 302), Beaufort West district of the Western Cape Province of South Africa (Haughton \& Boonstra 1929). Day et al. (2015) consider this locality high in the 

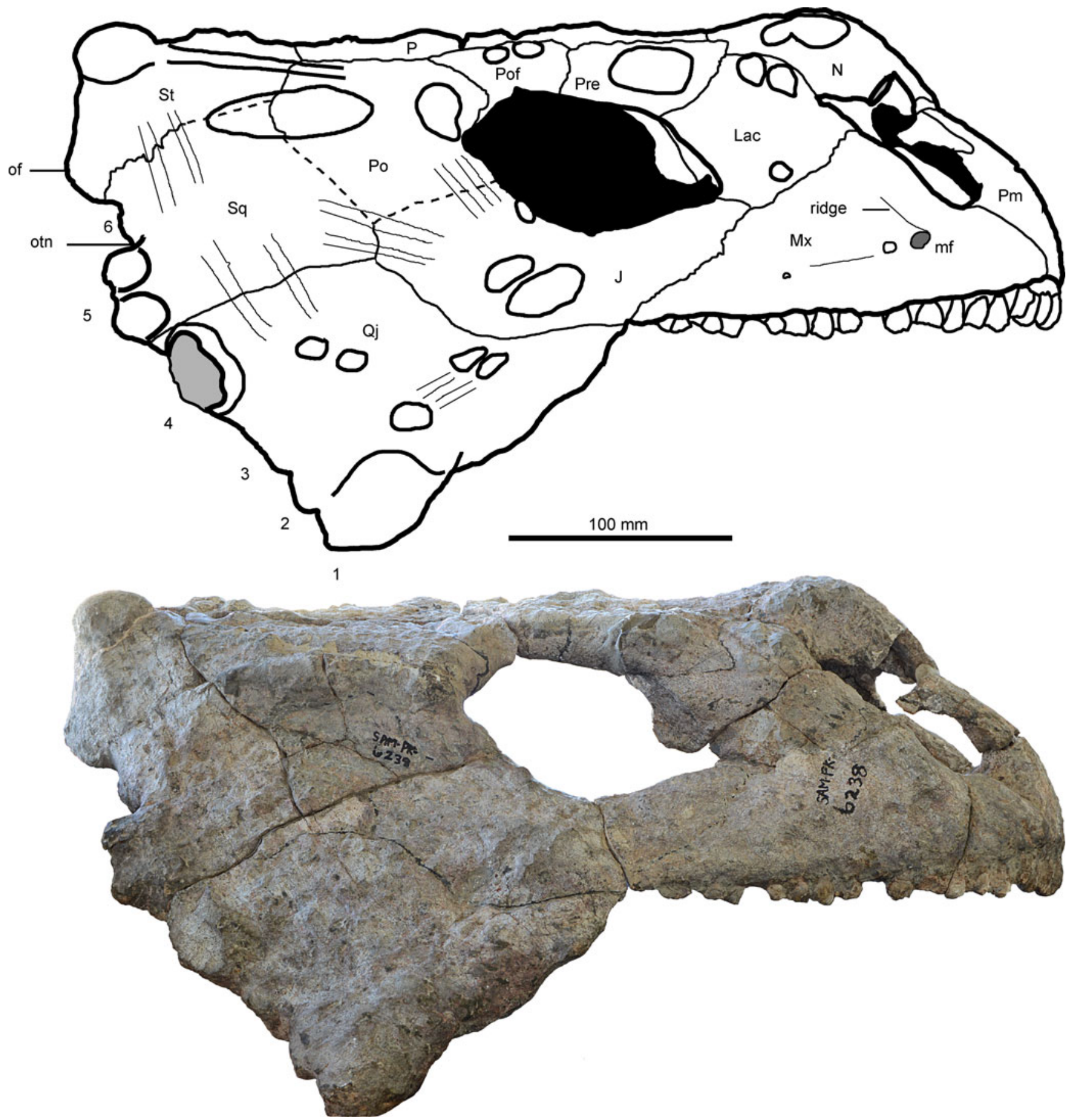

Figure 4 Photograph and interpretive drawing of the skull of a specimen of Nochelesaurus alexanderi (SAM-PK-6238, holotype of Dolichopareia angusta) in right lateral view. Abbreviations: $\mathrm{J}=$ jugal; Lac = lacrimal; $\mathrm{mf}=$ maxillary foramen; $\mathrm{Mx}=$ maxilla $\mathrm{N}=$ nasal; of $=$ occipital flange $;$ otn $=$ otic notch $\mathrm{P}=$ parietal; $\mathrm{Pm}=$ premaxilla; $\quad$ Po = postorbital; $\quad$ Pof $=$ postfrontal $; \quad$ Pre $=$ prefrontal $; \quad Q j=$ quadratojugal $; \quad S q=$ squamosal $; \quad \mathrm{St}=$ supratemporal.

Tapinocephalus Assemblage Zone, restricted to the uppermost Karelskraal Member of the Abrahamskraal Formation, and represents the highest stratigraphic occurrence of Nochelesaurus.

\subsection{Revised cranial diagnosis}

Nochelesaurus has one cranial autapomorphy: transversely wide postparietal.

Nochelesaurus is distinguished from co-occurring Tapinocephalus AZ pareiasaurs in having maxillary teeth with seven marginal cusps and a symmetrical cusp arrangement or an eighth, low, small, basal cusp on the mesial margin, creating a nonsymmetrical cusp arrangement; maxillary teeth with three to five vertical ridges on the lingual surface; up to ten cusps on mandibular teeth; mandibular teeth with non-symmetrical mesial and distal cusp arrangements due to extra, low, very small, mesial marginal cusp on certain teeth; snout relatively narrow (almost as high as wide); maxilla without a maxillary boss; more distinct cranial ornamentation (especially on the prefrontal, postfrontal and postorbital); frontal central boss large and distinct; narrowest cheek flange; corner cheek boss large and elongated, with a narrow neck proximally, a raised distal rim, and a pointed distal tip; posterior edge of the quadratojugal with distinct bosses that vary from horizontally flat and plate-like to medium sized, round, pointed bosses; gap on the posterior 

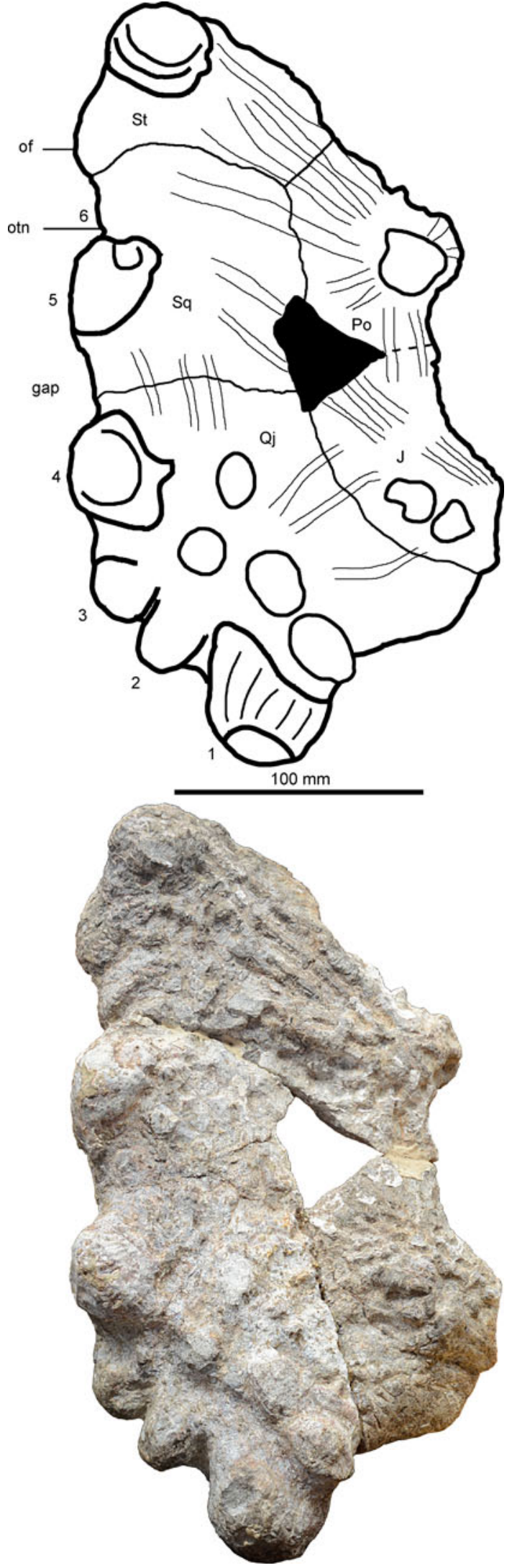

Figure 5 Photograph and interpretive drawing of the partial skull of a specimen of Nochelesaurus alexanderi (SAM-PK-6239A) in right lateral view. Abbreviations: $\mathbf{J}=$ jugal; of = occipital flange; otn = otic notch; Po = postorbital; $\mathrm{Qj}=$ quadratojugal $; \mathrm{Sq}=$ squamosal $; \mathrm{St}=$ supratemporal.

edge of the cheek separating the dorsal-most quadratojugal boss from the large squamosal boss; distal portion of the paroccipital process of the opisthotic low and smooth or with a dorsolaterally elongated and gently swollen posteroventral edge, lacking the dorsomedially elongated posterior process of Bradysaurus and Embrithosaurus; tubercles present on the ventral surface of the basisphenoid/ parabasisphenoid, just behind the basipterygoid processes.

Nochelesaurus differs from Bradysaurus in having vertical and narrow premaxilla and maxilla $(<5 \mathrm{~mm}$ wider than the tooth row), accommodating vertically oriented upper marginal teeth; 18 upper marginal teeth; low maxillary-lacrimal ridge with a sharp lateral edge, not reaching the lacrimal boss complex.

Nochelesaurus differs from Embrithosaurus in having postfrontal square and not mediolaterally elongated; all upper marginal teeth dorsoventrally elongated and mesiodistally narrow, with a three cusped central trident; all mandibular teeth dorsoventrally elongated, mesiodistally narrow; an incipient horizontal cingulum carrying medially placed cusp(s) on the lingual surface of certain mandibular teeth; lingual surface of mandibular teeth with one to three distinct vertical ridges.

\section{Cranial description}

\subsection{Skull roof}

Unless otherwise noted, this description of the skull roof is based on the holotype SAM-PK-6239. Reference to referred specimens (SAM-PK-6238, SAM-PK-6239A, CGP JA 109) is made where appropriate. On the holotype, the dorsal skull table and the right cheek and facial regions are preserved. Large amounts of white plaster have been used internally to reinforce the skull partially covering the internal surface of several bones. The skull roof of SAM-PK-6238 is partially preserved in three large fragments: the snout, a large right cheek fragment, and a small part of the dorsal skull table (articulated in Figs 2, 4, 7). SAM-PK-6239A consists of a large fragment of the right cheek. CGP JA 109 consists of most of a skull, comprising two large fragments held together with plaster, lacking the left snout, palate and the lower jaw.

All specimens (apart from the over prepared SAM-PK-6238) are heavily ornamented with distinct protruding bosses; long and rugose ridges, separated by depressions or furrows, and small circular pits. Most bones, apart from the premaxilla, maxilla and the squamosal, have one dominant large boss or a complex of smaller bosses, near the centre of the bone. The straight, rugose ridges form a distinct pattern, spreading radially out from a large central boss or a central complex of smaller bosses. Internally the bones of the skull are smooth, featureless and unornamented.

As in all basal South African pareiasaurs, a well-defined longitudinal ridge extends from the snout to the back of the skull and creates a sharp junction that separates the horizontally oriented, dorsal skull table, from the ventrolaterally oriented lateral facial and cheek regions. The longitudinal ridge is anteriorly formed by a string of bosses on the nasal, lacrimal, prefrontal, postfrontal and postorbital, and behind the orbit, by thickened, elongated ridges on the postorbital, squamosal and supratemporal. The posterior border of each cheek has five large protruding bosses: four on the quadratojugal and one on the squamosal.

Significant deformation affects three of the four skulls studied. The holotype skull is severely dorsoventrally crushed so that the dorsal skull table and the lateral face and cheek regions are flattened to appear almost on the same plane. The snout is low and much wider than high and if undeformed it would have been about as wide as high. The dorsal skull roof has also been displaced backwards, such that the right orbit and the external naris are posterodorsally elongated, instead of being circular and vertical respectively. SAM-PK-6238 is severely mediolaterally compressed resulting in the snout appearing much higher than wide and the pineal foramen appearing very narrow instead 


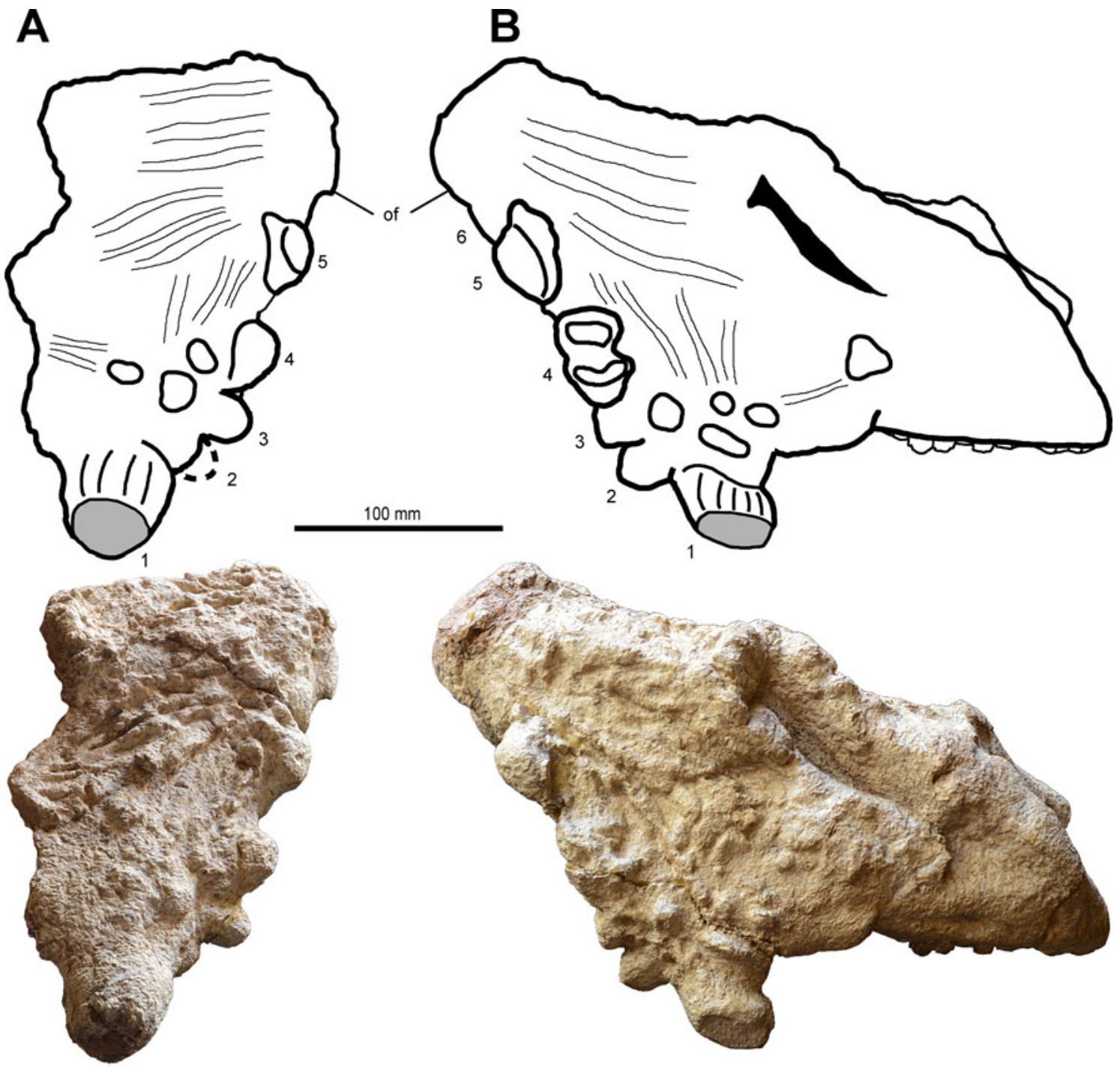

Figure 6 Photographs and interpretive drawings of the partial skull of a specimen of Nochelesaurus alexanderi (CGP JA 109) in (a) left lateral, and (b) right lateral view. Abbreviations: of $=$ occipital flange; otn $=$ otic notch .

of circular. The undistorted lower jaw is much wider than the mediolaterally compressed snout. The dorsal skull roof is also posteriorly displaced, creating a posterodorsally elongated right orbit and external naris. CGP JA 109 is severely dorsoventrally crushed and posteriorly displaced, with the right orbit appearing unnaturally narrow.

3.1.1 Premaxilla. The up side down T-shaped and smooth premaxilla is located at the anterior tip of the snout. On the floor of the external naris, the premaxilla forms the medial half of the anteroventral border of the external naris where an anteromedial longitudinal groove is present (Fig. 1).

The vertically ascending premaxillary process forms most of the internarial bar and the anteromedial corner of the external naris. In all undistorted basal South African pareiasaurs, the premaxillary portion of the internarial bar slopes vertically and slightly anterodorsally, but is vertically and slightly posterodorsally oriented in the holotype and SAM-PK-6238 as a result of the backwards deformation of these skulls (Figs 3, 4). Dorsomedially the premaxilla overlaps the nasal as a plate of bone and is clasped laterally by the descending processes of the nasal.

The premaxilla is narrow and forms a thin, vertical wall, slightly wider $(<5 \mathrm{~mm})$ than the three teeth it bears (see Marginal dentition). Sockets of the premaxillary teeth are more than twice the length of the exposed crowns, and very straight, and only slightly curved. As in the holotype of Embrithosaurus, tooth crowns point straight downwards with no medial infliction. This is different to the condition of Bradysaurus baini, in which teeth are obliquely horizontally oriented, where the premaxilla (and maxilla) is curved just above the tooth row, presenting a wide horizontally flattened area which accommodates curved, obliquely horizontally oriented tooth roots and sockets.

Internally, several centimetres above the tooth row, the premaxilla has a thin, horizontal flange that forms part of the palate, extending posteriorly behind the internarial bar (Fig. 7). This palatal flange of the premaxilla has a short transverse contact with the vomer and forms the anteromedial border of the internal naris and the anterior and lateral walls of the large, oval prepalatal foramen, limited posteriorly by the vomer.

3.1.2 Maxilla. The maxilla is triangular in lateral view. It is highest anteriorly and tapers posteriorly to form most of the anterolateral side of the face, but does not contribute to the orbital margin (Figs 3, 4). Externally the maxilla is a large, vertical, curved plate whereas internally, a small horizontal flange forms part of the palate. Anteriorly the maxilla forms the lateral half of the floor of the external naris. The posterior portion of the maxilla extends along the ventral margin of the skull to midway across the orbit, to just contact the quadratojugal (e.g., SAM-PK-6238, Fig. 4).

A parareptilian synapomorphy is the presence of an anterolateral maxillary foramen below the ventrolateral corner of the external naris, above the 3 rd or 4th maxillary tooth (Laurin \& 


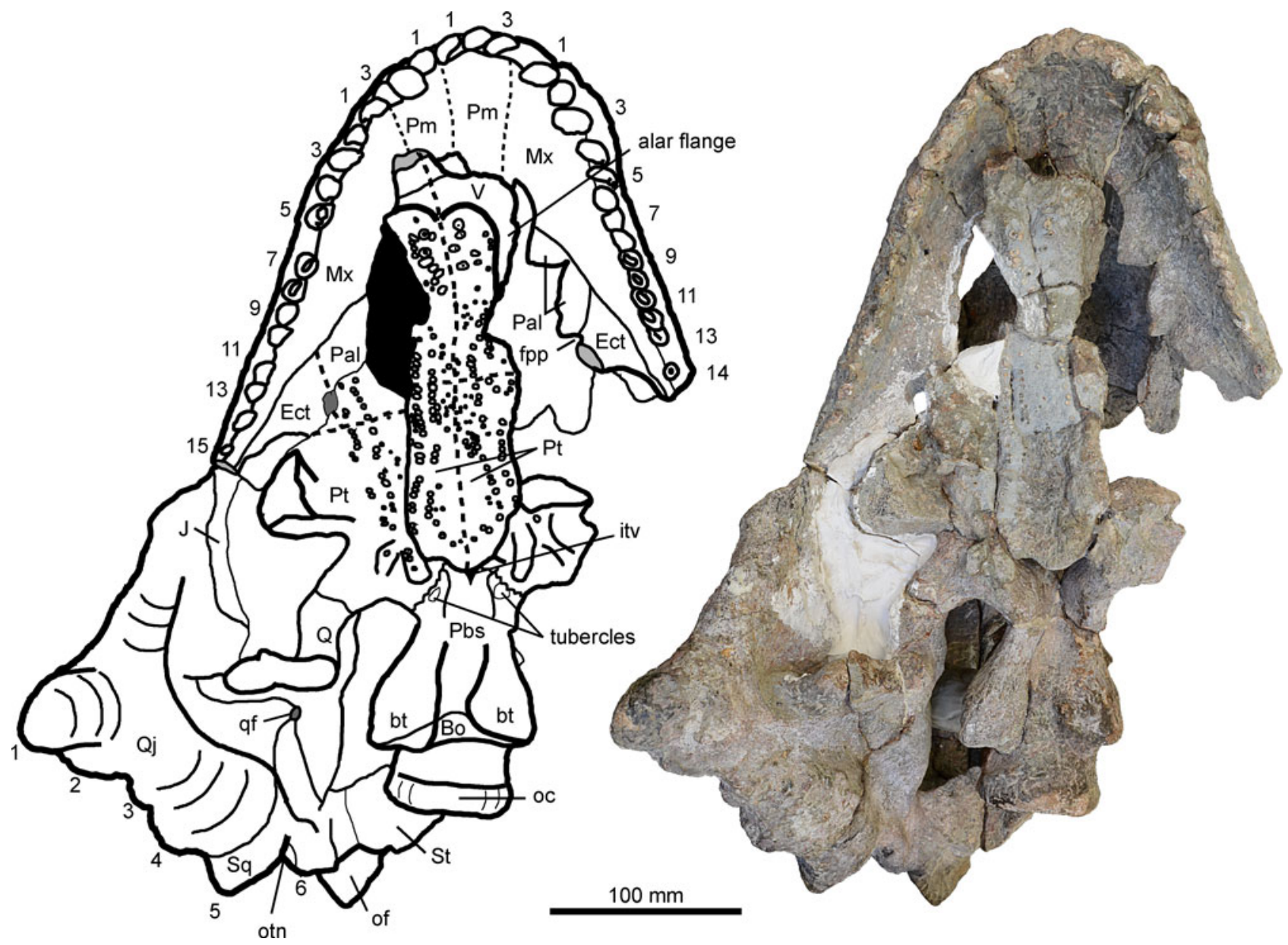

Figure 7 Photograph and interpretive drawing of the skull of a specimen of Nochelesaurus alexanderi (SAM-PK-6238, holotype of Dolichopareia angusta in ventral view. Abbreviations: $\mathrm{Bo}=$ basioccipital; $\mathrm{bt}=$ tubera basispheniodales (basal tubera); Ect = ectopterygoid; fpp = foramen palatinum posterius (suborbital vacuity); itv = interpterygoid vacuity; $\mathrm{J}=$ jugal; $\mathrm{Mx}=$ maxilla; oc $=$ occipital condyle; of $=$ occipital flange; otn $=$ otic notch; Pal = palatine; $\mathrm{Pbs}=$ parabasisphenoid; $\mathrm{Pm}=$ premaxilla; $\mathrm{Pt}=$ pterygoid; $\mathrm{Q}=$ quadrate; qf = quadrate foramen; $\mathrm{Qj}=$ quadratojugal; $\mathrm{Sq}=$ squamosal; $\mathrm{St}=$ supratemporal; $\mathrm{V}=$ vomer.

Reisz 1995). This foramen is very large (Figs 3, 4) and probably accommodated a branch of the trigeminal nerve as in Bunostegos (Tsuji et al. 2013). In SAM-PK-6238 this foramen is followed posteriorly by two smaller nutritive foramina (Fig. 4).

The anterolateral margin of the maxilla is strongly convex. Unlike all other basal South African pareiasaurs, no maxillary boss is present on the maxilla of Nochelesaurus, making this an important distinguishing feature. Dorsoventral crushing of the skull of the holotype has created the false appearance of a protruding maxillary boss above the large maxillary foramen (Figs 1, 2). All specimens of Nochelesaurus have a low, posterodorsally oriented, maxillary-lacrimal ridge $(20-25 \mathrm{~mm}$ wide) with a sharp lateral edge that follows the contour of the lateral border of the external naris (Figs 1, 3, 4). In stark contrast, Bradysaurus baini has a much wider and more swollen and bulging maxillary-lacrimal ridge ( $40 \mathrm{~mm}$ wide) that carries a large swollen maxillary boss and low (indistinct) lacrimal bosses. Embrithosaurus has a small (distinct) and pointed maxillary boss and small (distinct) lacrimal bosses.

The external surface of the maxilla of Nochelesaurus is smooth and unornamented, apart from a few short slightly raised rugose ridges and small oval to circular pits posteriorly, below the orbit. As in all basal South African pareiasaurs, a long, shallow, horizontal groove runs parallel to the tooth row on the external surface of the maxilla. The ventral surface of the maxilla of the holotype bears 15-16 teeth (see Marginal dentition). As in the premaxilla, the maxilla forms a narrow thin wall, only slightly wider $(<5 \mathrm{~mm})$ than the tooth sockets.
On the internal surface the maxilla forms a thin, horizontal, palatal flange extending medially, forming the anterolateral margin of the internal naris, and contacting the premaxilla anteromedially, the palatines posteromedially and the ectopterygoids posteriorly. Large and distinct, shallow circular pits are present internally (on the holotype), $20-30 \mathrm{~mm}$ above the base of each tooth of the premaxilla and maxilla, presumably for the alveolar canals.

3.1.3 Jugal. The elongated jugal forms the posteroventral, ventral and anteroventral margins of the orbit and the anteroventral portion of the lateral cheek. It contacts the lacrimal, maxilla, the quadratojugal, the squamosal and the postorbital.

The posterior half of the jugal, behind the orbit, is relatively thin and plate-like, whereas anteriorly the bone is much thicker, rounded and curved. In the orbital margin the jugal forms the flat, horizontal anteroventral part of the antorbital buttress and there is no vertical antorbital flange of the jugal, as reported for Scutosaurus (Lee 1994).

Two low bosses, arranged obliquely, are present on the lateral surface, immediately above the suture with the quadratojugal (Figs 3-5), with the anterior one being the largest. Straight rugose ridges radiate from these bosses: dorsally onto the postorbital, posterodorsally onto the squamosal, and posteriorly onto the quadratojugal. Higher on the jugal, a third, less distinct boss is present on the posteroventral orbital margin, just below the jugal-postorbital suture (Figs 3-5). Specimens of Embrithosaurus and Bradysaurus baini show similar arrangements of bosses and radiating ridges on the jugal. 


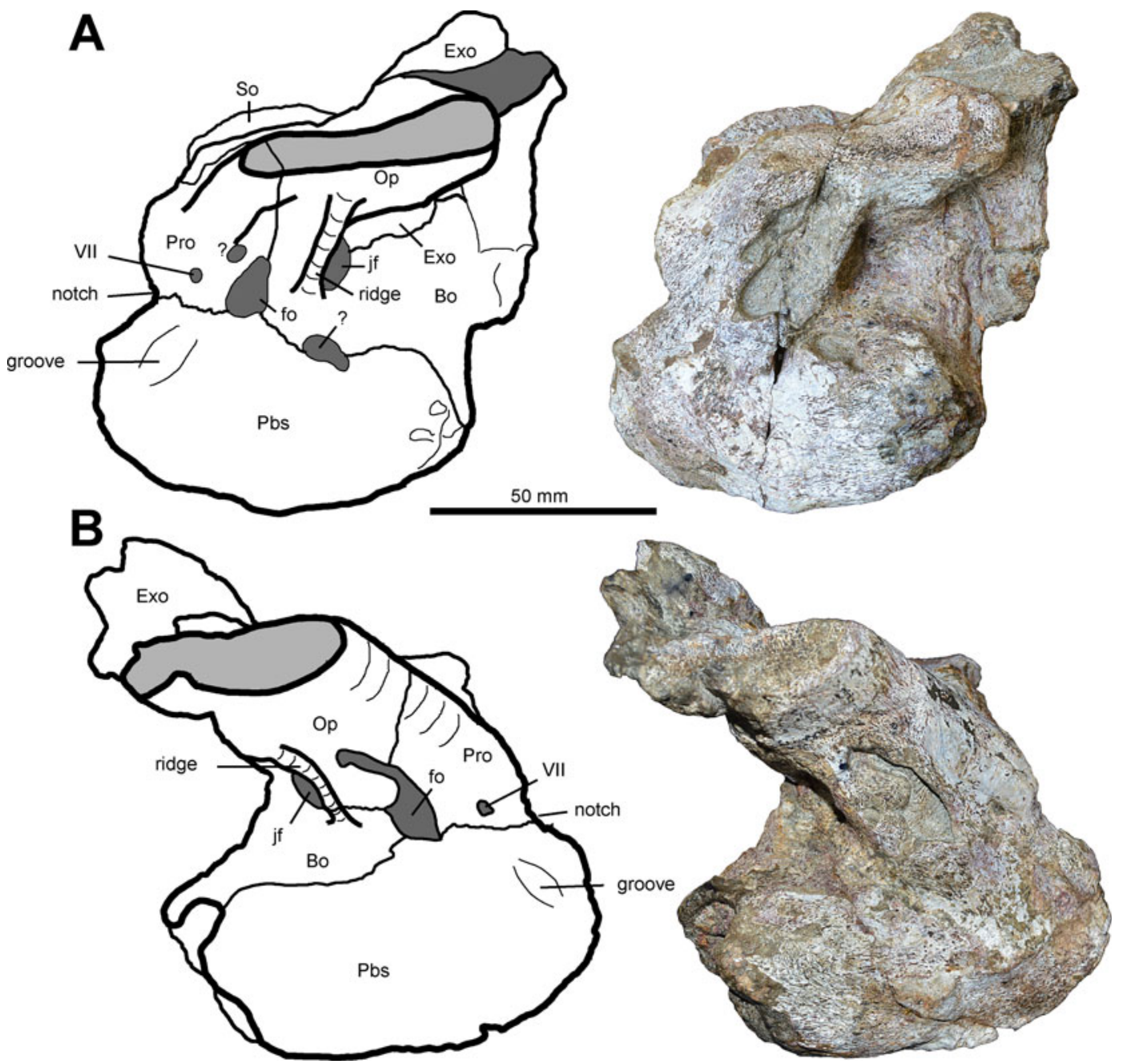

Figure 8 Photographs and interpretive drawings of the braincase of the holotype of Nochelesaurus alexanderi (SAM-PK-6239) in (a) left lateral view, and (b) right lateral view. Dorsal to the top of the page. Abbreviations: Bo = basioccipital; Exo = exoccipital; fo = fenestra ovalis; jf = jugular foramen; Op $=$ opisthotic Pbs $=$ parabasisphenoid Pro $=$ prootic $;$ So $=$ supraoccipital .

3.1.4 Quadratojugal. The quadratojugal is a large, flat, thin and roughly square plate of bone on the posteroventral corner of the skull where it forms most of the pareiasaurian ventrolateral 'cheek flange' behind and below the orbit. It extends well below the level of the tooth row (Figs 3-5).

A complex of three to four bosses on the lateral surface are arranged in a posterodorsally curved arc. Similar bosses are present in Embrithosaurus, but not in Bradysaurus baini where instead several long, low and rugose, partially fused ridges are present. These lateral bosses of the quadratojugal of Nochelesaurus are the most distinct of all basal South African pareiasaur species (but are eroded in SAM-PK-6238). Anterior to these bosses are several rugose ridges (also in Embrithosaurus and B. baini) which extend anterodorsally to reach the boss complex of the central jugal. As in all basal South African pareiasaurian taxa, vertical ridges on the posterodorsal portion of the lateral quadatojugal extend dorsally onto the squamosal. The ventral portion of the quadratojugal of Nochelesaurus is transversely narrow, unlike in B. baini where this region is greatly swollen by thickened partially fused rugose ridges.

The quadratojugal has four bosses on the posterior margin of the cheek (Figs 3-6). At the posteroventral corner is the largest and longest boss (almost twice as long as wide), posterolaterally directed and covered in rugose ridges that extend distally. Proximally, it has a narrowed neck and distally it swells to form a raised rim circumscribing the boss.. In contrast, the corner boss of Embrithosaurus and Bradysaurus baini is short and round, only slightly longer than wide, more bulbous, lacks a narrow proximal neck and raised distal rim, ends with a relatively blunt distal tip, and has no distinct rugose ridges. Above the large corner boss of Nochelesaurus are either one or two small, round to pointed bosses which are posteriorly directed. The number of small bosses varies between individuals and even bilaterally on the same individual (also in B. baini specimen SAM-PK-5624 which shows bilateral asymmetry).Dorsally there is a much larger boss (comprising two fused bosses in the holotype) posterolaterally directed, that has a long anterior projection on the lateral surface of the quadratojugal. This dorsal-most quadratojugal boss and the large squamosal boss are separated by a high gap $(30-40 \mathrm{~mm})$ through which the quadratojugal-squamosal suture runs. This gap is found on the holotype, SAM-PK-6239A and CGP JA-109 (but not in SAM-PK-6238) and is therefore a feature of Nochelesaurus. A similar gap is also present in a specimen of $B$. baini (SAM-PK-5002).

The posterior portion of the quadratojugal is mediolaterally narrow compared to similarly sized Bradysaurus baini specimens which have a much wider posterior quadratojugal.

The ventral border of the cheek of the holotype is oriented anterodorsally and slopes $33^{\circ}$ below the level of the tooth row, similar to Embrithosaurus $\left(29^{\circ}\right)$, but unlike Bradysaurus which may have a much shallower slope $\left(20^{\circ}\right)$ and therefore a smaller cheek. In Nochelesaurus, as is the case in all basal 


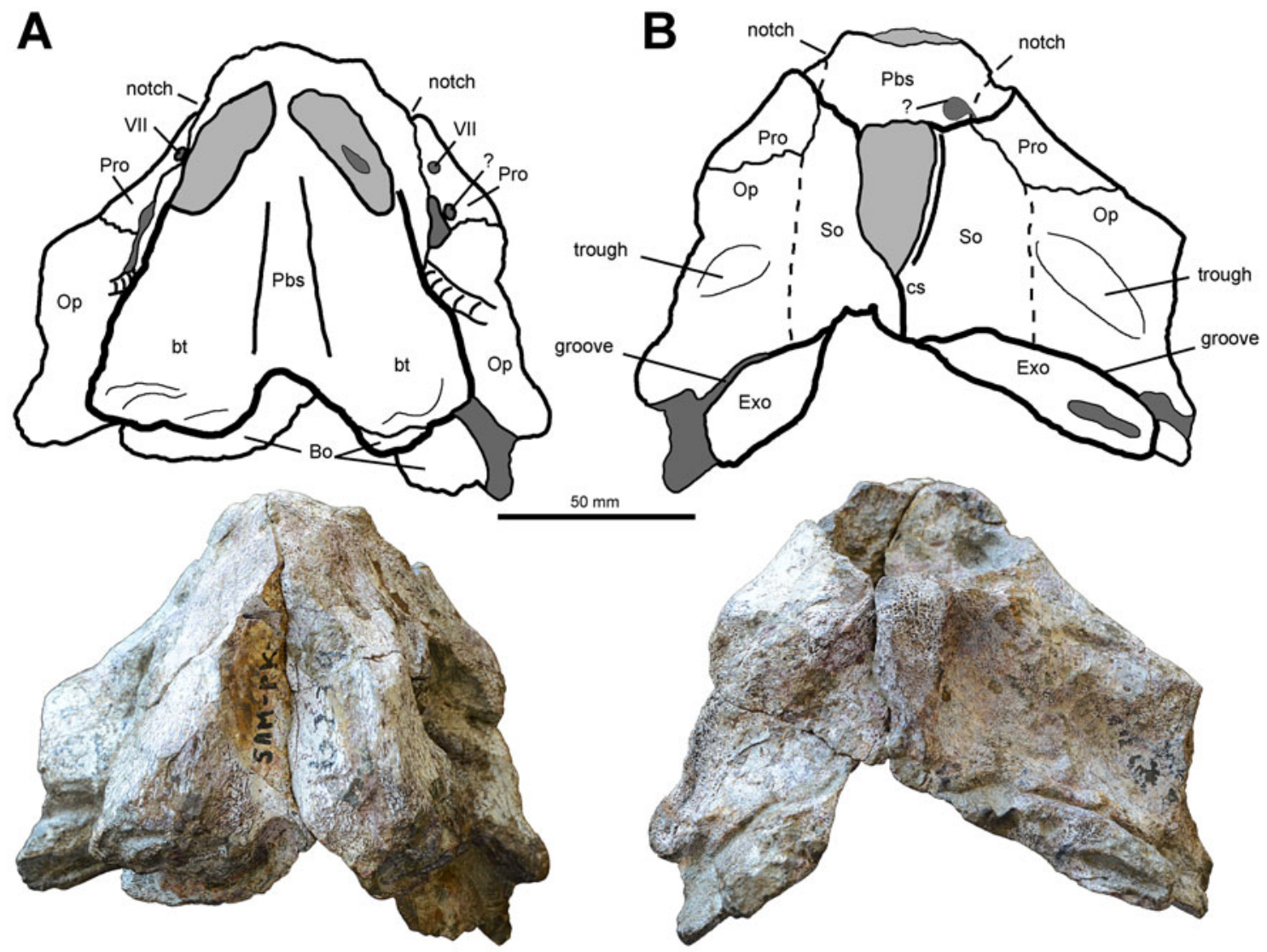

Figure 9 Photographs and interpretive drawings of the braincase of the holotype of Nochelesaurus alexanderi (SAM-PK-6239) in (A) ventral view, and (B) dorsal view. Anterior to the top of the page. Abbreviations: Bo = basioccipital; bt = tubera basispheniodales (basal tubera); cs = crista supraoccipitalis; Exo = exoccipital; Op = opisthotic; Pbs = parabasisphenoid; Pro = prootic; So = supraoccipital.

South African pareiasaurs, there are no bosses on the ventral edge of the cheek, instead there is a low convex bulge over the entire surface.

Medially, the quadratojugal sends out a thick vertical flange which meets the squamosal at a large quadrate foramen. Below the quadrate foramen, the quadratojugal contacts the vertical ramus of the quadrate.

3.1.5 Squamosal. The squamosal is a flat plate-like bone forming most of the posterodorsal portion of the cheek (Figs 3-5) and fits between the dorsal supratemporal, the anterior postorbital and jugal and the ventral quadratojugal. As in all basal South African pareiasaurs, the longitudinally sharp junction between the dorsal skull table and the lateral side of the skull passes through the dorsal-most part of the squamosal, just below the squamosal-supratemporal suture.

The lateral surface of the squamosal is greatly ornamented, but lacking the central boss or complex of central bosses, which is found in more derived pareiasaurs (e.g., Scutosaurus, Lee 1994; Pareiasuchus nasicornis, Lee et al. 1997; Deltavjatia, Tsuji 2013). Anteroventrally oriented, thick rugose ridges are present anteriorly, and much thinner, vertically oriented ridges centrally and posteriorly. Numerous small pits and depressions are also present. Embrithosaurus and Bradysaurus baini have a similar arrangement of ridges and lack a central boss on the lateral surface of the squamosal (contra Lee 1994, 1997a, who illustrated the central boss complex in Bradysaurus baini using the holotype and SAM-PK-5002).

The posterior edge of the squamosal is dominated by a very large boss. This boss is irregularly shaped, often double lobed (dorsal and ventral projections), and higher than wide. When double lobed (Figs 3, 4) each lobe extends anteriorly 20-30 $\mathrm{mm}$ onto the lateral surface. Similar anterior extensions are also present in Embrithosaurus and Bradysaurus; however the height of the boss is greatest in Nochelesaurus.

As in Embrithosaurus, a deep horizontal otic notch outlined by a raised rim is present in Nochelesaurus (SAM-PK-6238) and extends a few centimetres medially and anteriorly along the internal surface of the squamosal. Above the notch the posterior edge of the squamosal bears a second, smaller boss (absent in the holotype, probably due to poor preservation) (Figs 4, 5). This second boss is rare but is present in a few other specimens of all basal South African pareiasaurian species (e.g., Bradysaurus baini SAM-PK-5002).

The extreme posterodorsal corner of the squamosal forms the lateral-most portion of the occipital flange and is vertically oriented with a sharp posterior edge. Medial to the posteroventral edge of the occipital flange, the squamosal has sutural contact with the ventral portion of the paroccipital process of the opisthotic and below it forms a thick vertical flange along with the quadratojugal.

3.1.6 Lacrimal. The lacrimal is roughly rectangular extending from the external naris, where it forms a large portion of the dorsolateral border, to the orbit where it forms a small part of the anterior margin. It sutures with the nasal, prefrontal, jugal and maxilla. On the orbital margin, the lacrimal forms the anterolateral part of the antorbital buttress where it shares a long suture with the descending flange of the prefrontal (Fig. 4) (as in Embrithosaurus).

Distinct cranial ornamentation covers the lacrimals, a small boss is present near the anteroventral corner of the orbit, and two distinct bosses are high on the lacrimal, transverse to each other near the nasal-prefrontal contact. Embrithosaurus and Bradysaurus have only the higher placed larger bosses (though much less distinct in Bradysaurus baini). The maxillary-lacrimal 

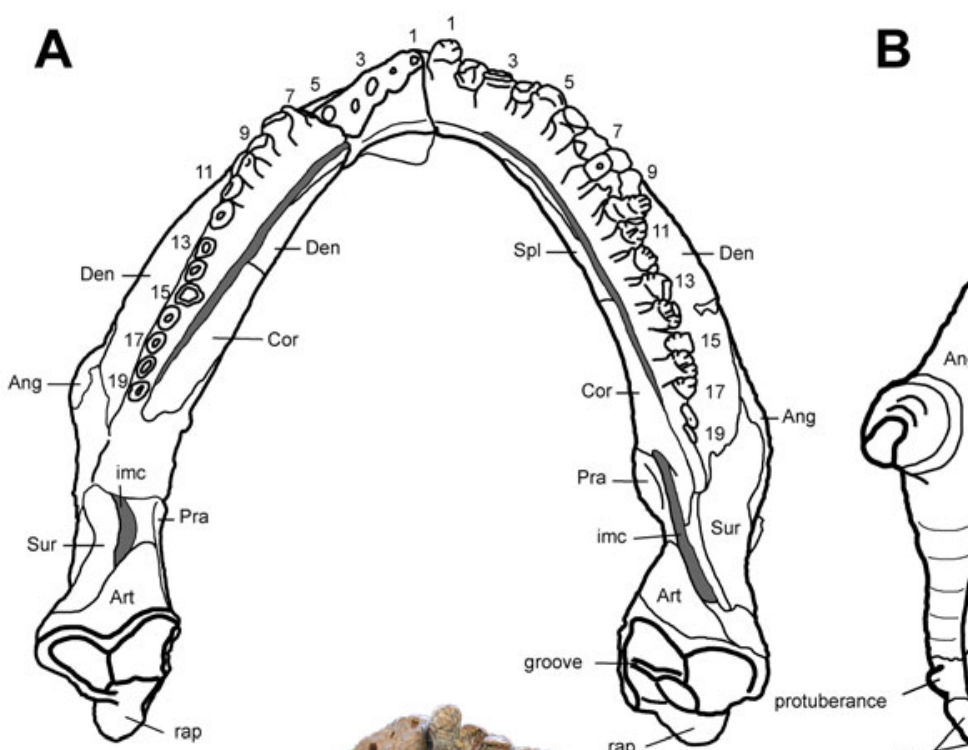

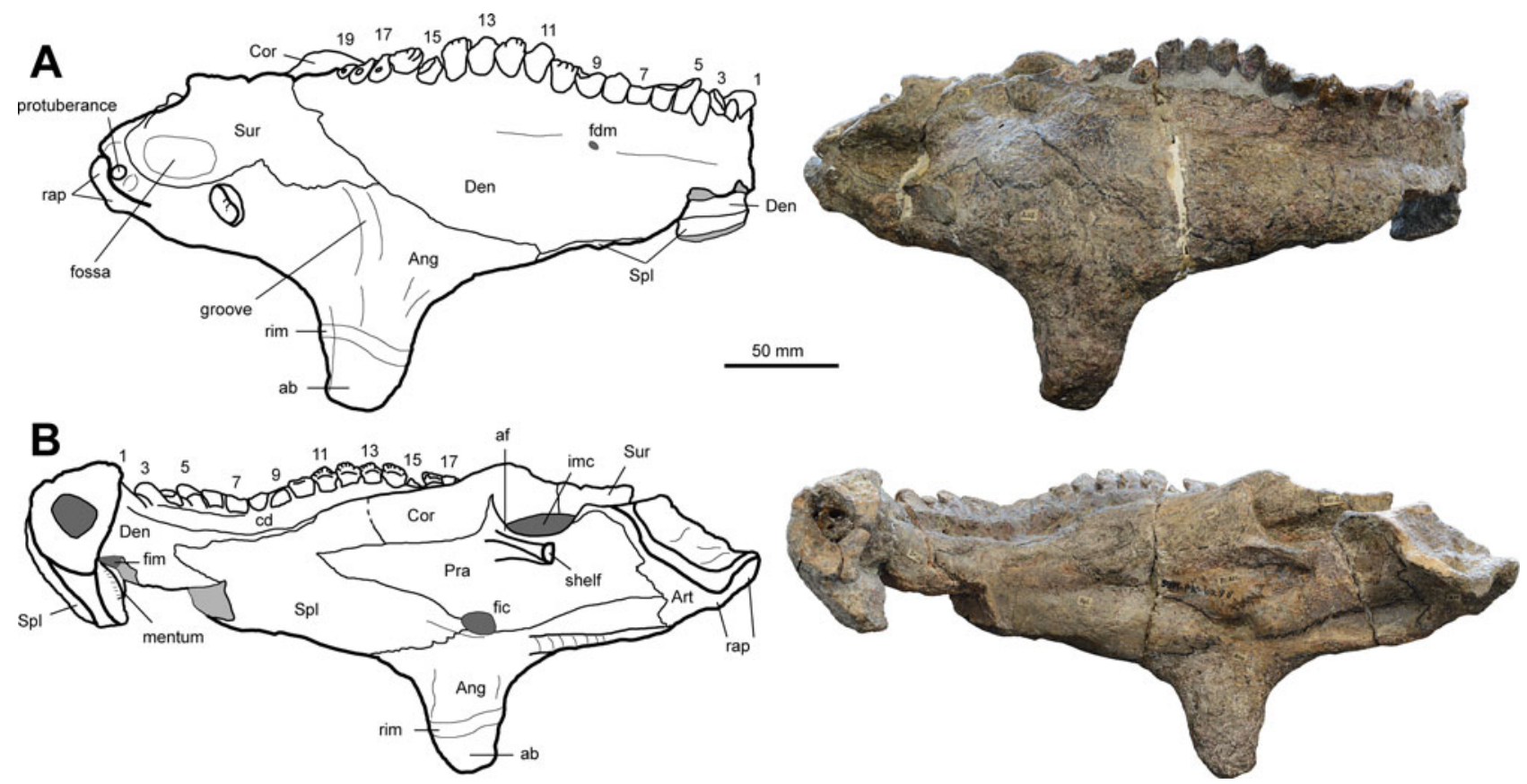

Figure 11 Photographs and interpretive drawings of the right lower jaw of a specimen of Nochelesaurus alexanderi (SAM-PK-6238, holotype of Dolichopareia angusta) in (a) lateral view, and (b) medial view. Abbreviations: ab = angular boss; af = adductor fossa; Ang = angular; Art = articular; cd = crista dentalis; Cor $=$ coronoid; Den $=$ dentary; $\mathrm{fdm}=$ foramen dentofaciale majus; fic $=$ foramen intermandibularis caudalis; fim $=$ foramen intermandibularis medius; imc = intra-mandibular cavity; $r a p=$ retroarticular process; $\mathrm{Spl}=$ splenial; Sur = surangular.

the cheek onto the squamosal, the other three extend posterodorsally and medially towards the central boss of the supratemporal. The three higher ridges are on the swollen, sharp junction between the dorsal skull table and lateral cheeks. Similar ridges are found in Embrithosaurus and Bradysaurus baini.

3.1.10 Nasal. The nasal is roughly triangular (Figs 1,2) and tapers anteriorly. It has a long, straight, longitudinal midline suture with its contralateral element, a posterior suture with the frontal, and contacts the prefrontal posterolaterally and the lacrimal anterolaterally.

A long, thin, anteriorly tapering descending processes of the nasal forms the dorsomedial border of the external naris and a small dorsal portion of the internarial bar (Fig. 1). Dorsoventral compression of holotype and SAM-PK-6238 have oriented the dorsal half of the internarial bar horizontally (Figs 3, 4). Undeformed it would have been more vertical with a slight posterodorsal orientation.

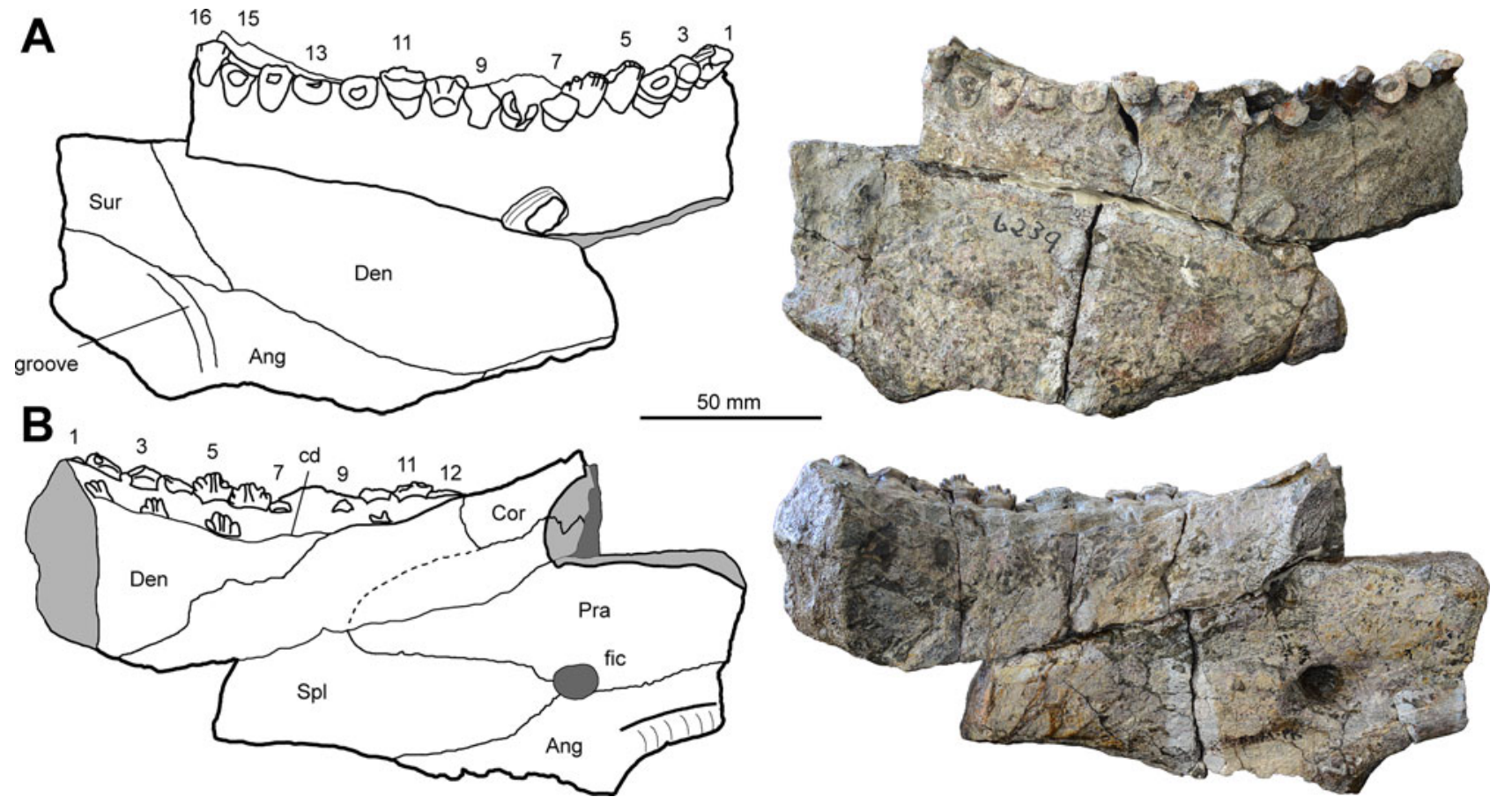

Figure 12 Photographs and interpretive drawings of the right lower jaw fragment of the holotype of Nochelesaurus alexanderi (SAM-PK-6239) in (a) lateral view, and (b) medial view. Abbreviations: Ang = angular; cd = crista dentalis; Cor = coronoid; Den = dentary; fic = foramen intermandibularis caudalis; Pra = prearticular; Spl = splenial; Sur = surangular. 


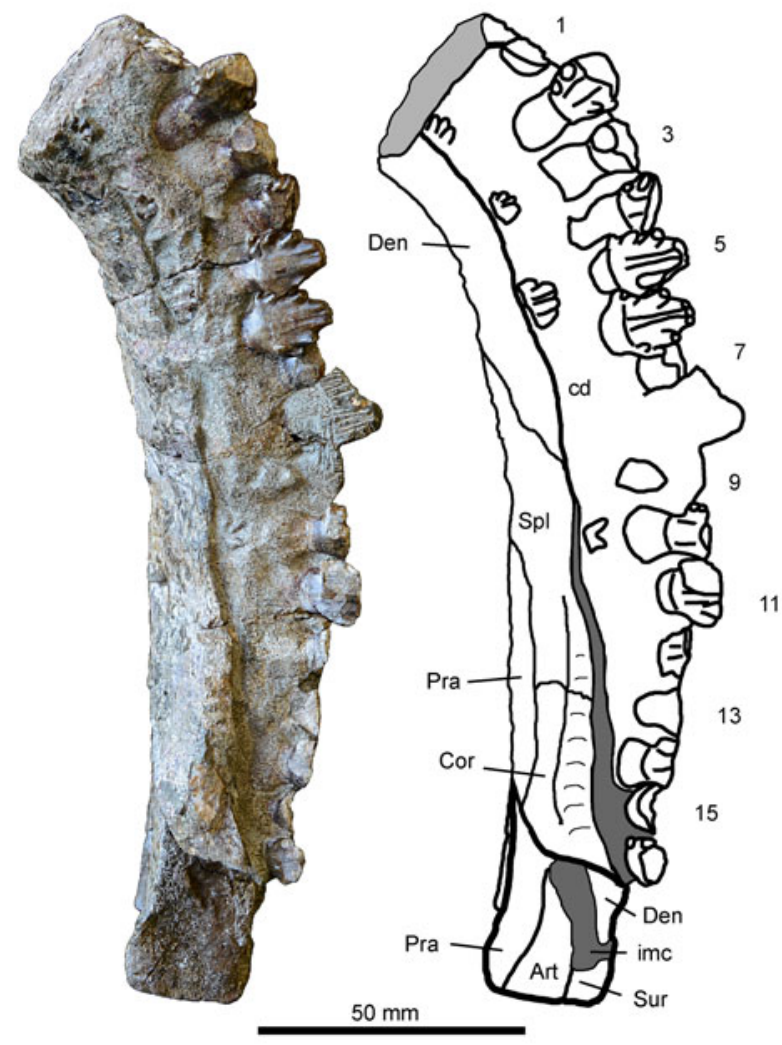

Figure 13 Photograph and interpretive drawing of the right lower jaw fragment of the holotype of Nochelesaurus alexanderi (SAM-PK-6239) in dorsal view. Anterior to the top of the page. Abbreviations: Art = articular; cd = crista dentalis; Cor = coronoid; Den = dentary; imc $=$ intra-mandibular cavity; $\quad$ Pra $=$ prearticular; $\quad$ Spl $=$ splenial; $\quad$ Sur $=$ surangular.

As seen in all basal South African pareiasaurian taxa a prominent anteromedially elongated boss is present at the centre of the nasal (Figs 1,2). Also as in all basal taxa, Nochelesaurus has two small ridges (nasal tab-like processes) radiating from the boss, a

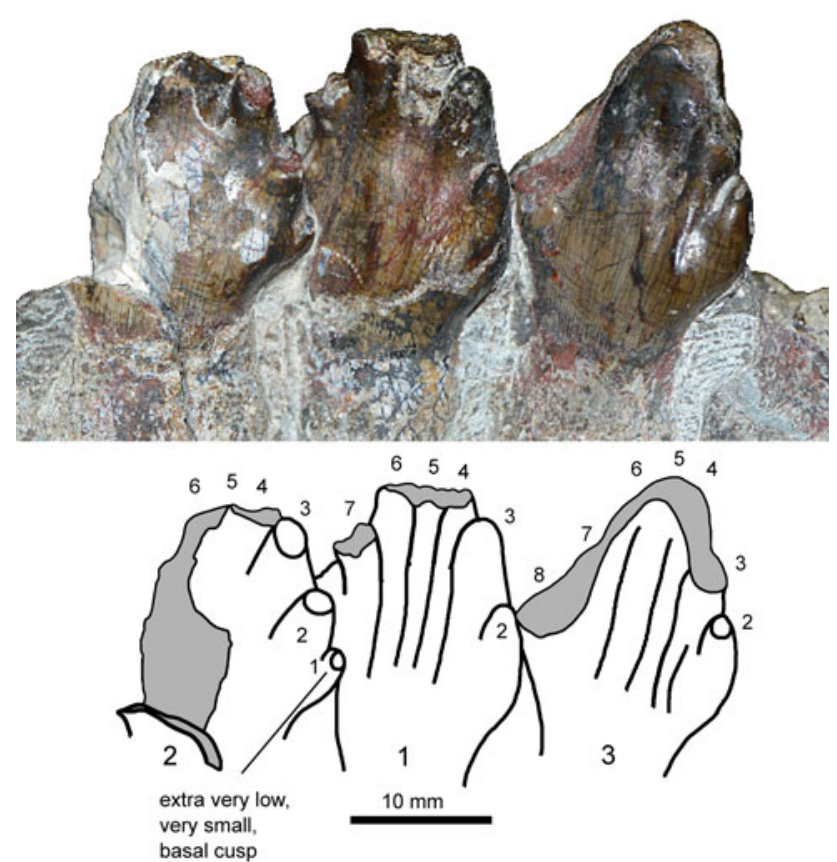

Figure 14 Photograph and interpretive drawing of upper right 3rd premaxillary and 1st and 2nd maxillary teeth of the holotype of Nochelesaurus alexanderi (SAM-PK-6239) in medial view. posterolateral tab and posteromedial tab (Figs 1,2). Most specimens of Bradysaurus and Embrithosaurus carry a third anterolateral tab-like process above the external naris, which is absent in most specimens of Nochelesaurus, but is present on the right side of one skull of Nochelesaurus (CGP JA 109).

A large, wide and irregular midline boss is present on the holotype at the fronto-nasal junction (Fig. 1). Referred Nochelesaurus specimen SAM-PK-6238 was noted by Haughton \& Boonstra (1929) as possessing a similar median boss, but we agree with Lee $(1994,1997$ a) that the boss in that specimen is a taphonomic artefact caused by mediolateral compression of the skull and resultant buckling of the paired nasal bones at the midline. We have not observed a midline boss on any other basal South African pareiasaur specimen.

Internally, the nasal has a narrow, longitudinally oriented ridge which tapers posteriorly from the dorsal border of the external naris, reaching a small deep notch (both features are also present in the holotype of Embrithosaurus).

3.1.11 Frontal. The horizontal frontal is rectangular and forms a large portion of the anteromedial dorsal skull table and is almost twice as long as wide. The frontals contact the nasals, prefrontals, postfrontals and the parietals, and, as in all pareiasaurs, and do not contribute to the orbital rim.

At the centre of the frontals is a large boss (mostly sheared off on the left side of the holotype) with rugose radial ridges. The same radial pattern of rugose ridges from the centre of the frontal, radiate from a very small central tubercle in Embrithosaurus and from an indistinct, low swelling in most specimens of Bradysaurus baini. A large, low boss is present at the posterolateral corner of the frontal, as in all basal South African pareiasaurian taxa. In Nochelesaurus this boss is separated from the bosses of the postfrontal by a narrow groove along the frontalpostfrontal contact. In Embrithosaurus and Bradysaurus baini this frontal boss, and the orbital marginal bosses of the postfrontal, coalesce into a single large continuous boss, but this may be the result of imperfect preservation and preparation.

The internal surface of the frontal of Nochelesaurus is smooth except for a short, longitudinal ridge near the centre of the bone, which is also present in Embrithosaurus. Posteromedially the sphenethmoid sutures transversely with the frontal.

3.1.12 Parietal. The parietal forms most of the posteromedial skull table. The bone is pentagonal, horizontally flat to slightly convex. The parietal sutures with the frontal, postfrontal, postorbital, supratemporal and the postparietal.

One low boss is present at the centre of the parietal (Figs 1,2) from which distinct rugose ridges radiate onto all neighbouring elements. Small to large circular pits are present between the ridges. The oblique posterolateral ridges are the thickest and reach the large supratemporal boss. All these features are present in all basal South African pareiasaurs.

A large circular pineal foramen is present on the midline suture and it is outlined by three ridges emanating from the central parietal boss. As in all basal South African pareiasaurs, the pineal foramen is situated very close to the frontal-parietal suture, within the anterior third of the parietal. Internally the parietal sutures anteriorly with the posterior part of the sphenethmoid bone and posteriorly with the ventral process of the postparietal.

3.1.13 Postparietal. The postparietal forms the median portion of the posterior part of the dorsal skull table. It is a large rectangular unpaired element, mediolaterally expanded to approximately twice as wide as long, in stark contrast to the smaller, square shaped, approximately as wide as long condition in Embrithosaurus and Bradysaurus baini and indeed all other pareiasaurs. The very wide postparietal of Nochelesaurus is autapomorphic and fills the area of the absent supernumerary bones. The anterior sutural contact with the parietal is oblique and 


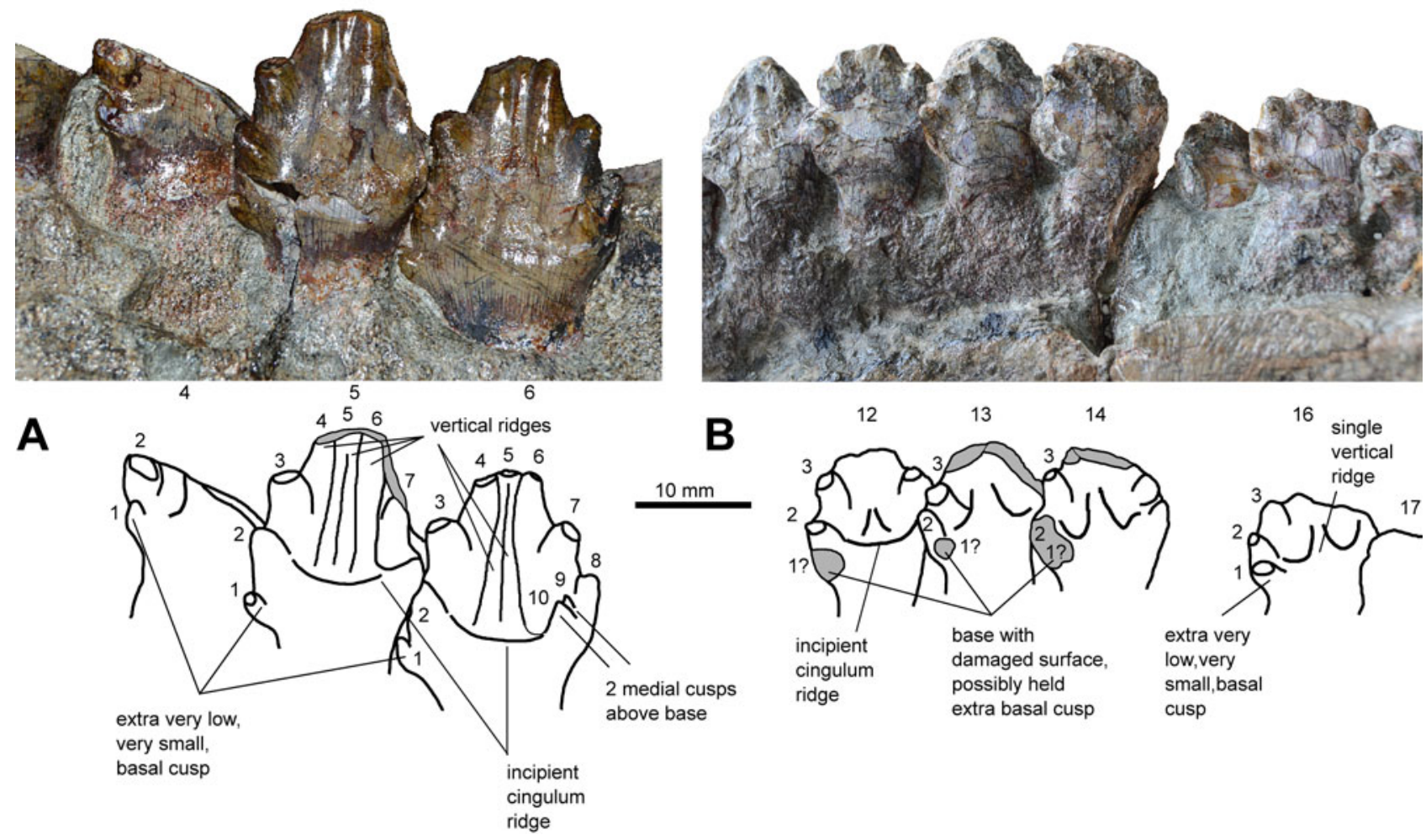

Figure 15 Photographs and interpretive drawings of (a), the 4th, 5th and 6th lower right mandibular teeth of the holotype of Nochelesaurus alexanderi (SAM-PK-6239) in medial view, and (b) the 11th to 17th lower right mandibular teeth of a specimen of Nochelesaurus alexanderi (SAM-PK-6238, holotype of Dolichopareia angusta) in medial view.

curved. Lateral contact with the supratemporal is short and straight.

In Nochelesaurus, the wide postparietal bears four bosses: two smaller, indistinct bosses in the anterolateral corners, and two larger bosses, irregularly shaped with tab-like processes in the posterolateral corners. These bosses are not present on the narrower postparietals of Embrithosaurus and Bradysaurus baini as instead they occur on the adjacent supratemporals. Medial to the bosses, either side of the midline, are shallow longitudinal postparietal depressions on Nochelesaurus. In B. baini and Embrithosaurus these depressions mark the postparietal-supratemporal suture. Thick longitudinal rugose ridges (posterior extensions from each parietal central boss) cover the anteromedial surface of the postparietal.

The posterior border of the postparietal curves downwards to form a short ventral flange which overhangs the occiput and continues laterally on the supratemporal and squamosal to form a frill in all the basal South African pareiasaurs.

Ventrally, the posterior postparietal forms a thickened bar of bone that follows the contours of the posterior edge of the skull and persists laterally onto each supratemporal. Anterior to this bar, SAM-PK-6238 preserves the descending process of the postparietal as a thick pillar, diamond-shaped in cross section, with anterior and posteriorly tapering edges as in all other pareiasaurs. The triangular cross section of this process in Embrithosaurus and Bradysaurus baini is the result of deformation.

3.1.14 Supratemporal. The supratemporal is a very thick and robust bone that forms the posterolateral corners of the dorsal skull table. It is roughly square and sutures with the postparietal, the parietals, postorbitals and squamosals. The largest boss on the skull of Nochelesaurus is on the posterolateral corner of the supratemporal (Figs 1-5). Preservation of this boss is incomplete on the holotype, as is the case in many Tapinocephalus AZ pareiasaur specimens.
Thick rugose ridges extend outwards onto adjacent bones from each large supratemporal boss: two to three extend anteriorly towards the postorbital; two to three oblique ridges anteromedially towards the parietal; and two ridges extend medially towards the postparietal. This pattern is consistent amongst all basal South African pareiasaurs.

Ventrally, the thickened bar of bone of the posterior edge of the skull is present on the supratemporal. Medially, the width of the bar on the supratemporal is the same on the adjacent postparietal but laterally it widens to form a ventrally directed flange. Dorsally, this flange sutures with the distal end of the paroccipital process of the opisthotic, and ventrally with the squamosal.

\subsection{Palate}

The palate of Nochelesaurus is well above the level of the tooth row. Only an isolated fragment of the pterygoid (not figured) and small portions of the internal palatal flanges of the premaxilla, maxilla, and partial vomer attached to the skull are preserved in the holotype. Most of the palate and braincase of SAM-PK-6238 are preserved in articulation (Fig. 7). Specimen CGP JA 109 has only an unprepared partial right palate preserved. Therefore, unless otherwise stated, the palatal description is based on SAM-PK-6238.

3.2.1 Vomer. The vomer is located behind the palatal flanges of the premaxilla, well behind the prepalatal foramen and posteriorly it sutures with the pterygoid (only detectable dorsally). As in Embrithosaurus, the dorsal surface of the vomer bears a longitudinally oriented midline ridge ( $20 \mathrm{~mm}$ high), an anterior continuation of the ridge from the pterygoid. Either side of this ridge, the alar flange of the vomer (Damiani \& Modesto 2001) is much thinner and flatter and forms the medial border of the internal naris (Fig. 7).

Anteroventrally the vomer bears several large denticles (3-4 $\mathrm{mm}$ diameter) roughly arranged in two parallel rows either side of the midline. They are positioned within $20 \mathrm{~mm}$ of the midline, 
where the vomer is thickest, and do not occur laterally on the thin alar flange. Posteroventrally are much smaller denticles (1-2 mm diameter), also roughly arranged into two rows either side of the midline, that extend posteriorly onto the pterygoid. Several smaller denticles $(<1 \mathrm{~mm}$ diameter) are interspersed and scattered irregularly around the anterior and posterior rows.

3.2.2 Palatine. The palatine is a small flat bone located anterolaterally on the palate. It forms the posterolateral border of the internal naris and has a long suture with the palatal flange of the maxilla (Fig. 7). Posterolaterally the palatine contacts the ectopterygoid and also forms the anteromedial and medial border of the large suborbital vacuity and the ectopterygoid forms the anterolateral, lateral and posterior border of this foramen. A double row of obliquely directed denticles, carried primarily on the pterygoid (see Pterygoid) extend anterolaterally onto the posterior portion of the palatine.

3.2.3 Pterygoid. The pterygoid forms the posteromedial portion of the palate. Anteriorly it comprises a horizontal plate containing multiple rows of denticles and posteriorly it extends as two processes: one posterolaterally to connect to the side of the skull and one posteromedially to the braincase.

Ventrally, two rows of longitudinal denticles are present on the pterygoid plate either side of the midline. Each row contains 20 25 teeth (1-2 mm diameter) converging anteriorly towards the midline. Medial to these teeth is a shallow longitudinal midline depression with smaller randomly scattered teeth. Posteriorly, the medial rows of denticles follow the convex contour of the anterior border of the interpterygoid vacuity to curve medially to meet at the midline. An obliquely oriented double row of about 15 denticles extends anterolaterally onto the palatine from the posterior part of the pterygoid. All these features of the ventral pterygoid of Nochelesaurus are also found in Embrithosaurus and Bradysaurus baini.

Posteromedially the pterygoid forms the anterior and anterolateral borders of the interpterygoid vacuity, where it shares a solid suture with the basipterygoid process of the parabasisphenoid. The interpterygoid vacuity is roughly rectangular in ventral view, transversely wide, with an anterior border that is convexly curved and points posteriorly, agreeing with the condition of Embrithosaurus and Bradysaurus baini. A deep, round notch ( $30 \mathrm{~mm}$ wide, $10 \mathrm{~mm}$ deep) is present on the dorsal surface of the pterygoid on either side of the anterolateral corner of interpterygoid vacuity.

SAM-PK-6238 preserves a partial right transverse flange of the pterygoid. The lateral edge is curved, directed ventrally, and extends $20-30 \mathrm{~mm}$ below the level of the rest of the palate. The posteroventral edge is flattened to produce a sharp ventrally projecting ridge (Fig. 7). Specimen CGP JA 109 has a row of 10 15 large denticles on the posterior edges of both transverse processes, and these denticles are also present in Embrithosaurus and Bradysaurus baini. The transverse process extends laterally to almost reach the inner surface of the jugal, but this close proximity is a result of the mediolateral compression of the skull. Posterolaterally the pterygoid sutures with the quadrate along the vertically oriented quadrate ramus of the pterygoid, which is thicker ventrally than dorsally and roughly triangular in cross section.

3.2.4 Ectopterygoid. The ectopterygoid is the smallest bone of the palate and is located lateral to the palatine. It is a flat horizontal flange, medially narrow where it has a short suture with the palatine, and broadens laterally where it has a long suture with the maxilla. Anteromedially, the suture with the palatine passes through the large open foramen palatinum posterius. The posterior contact with the pterygoid is difficult to identify with certainty (Fig. 7).

3.2.5 Quadrate. The quadrate is a vertically oriented, transversely directed plate-like bone that connects the palate to the inner skull roof (Fig. 7). Medially it sutures with the pterygoid on the quadrate ramus and extends posterolaterally. Here the quadrate is thick and triangular in cross section (thicker ventrally, tapering dorsally). The posteromedial side of the quadrate of SAM-PK-6238 presents a long, oblique shelf which creates an anterior embayment as in all other co-occurring South African pareiasaurs. Laterally the quadrate forms a tall, thin flange, along with the squamosal and quadratojugal, that connects perpendicularly to the inner surface of the cheeks. A large oval quadrate foramen is present on the posterior facing lateral portion of the quadrate, at the intersection of the quadrate, squamosal and quadratojugal. The jaw articulation is transversely expanded, anteroposteriorly narrow, and consists of a small medial condyle and a larger and wider lateral condyle which are separated by a shallow groove.

\subsection{Braincase and occiput}

The holotype of Nochelesaurus preserves a large isolated fragment comprising most of the braincase (Figs 8, 9). The occipital condyle is not preserved, whereas the supraoccipital and the left paroccipital process of the opisthotic are partially preserved. Inside the skull roof, the sphenethmoid is sutured to the ventral surface of the frontal and parietal. The distal portion of the left paroccipital process of the opisthotic is sutured to the inner surface of the supratemporal and squamosal. The cavum cranii is fully prepared in the holotype and SAM-PK-6238 which both serve as the basis for this description. Only the paroccipital processes of the opisthotics of CGP JA 109 are well preserved.

3.3.1 Sphenethmoid (pleurosphenoid). Called the pleurosphenoid by Lee (1994, Lee et al. 1997) this bone is termed the sphenethmoid or interorbital septum by most other pareiasaurian researchers (e.g., Watson 1914; Boonstra 1934; Tsuji 2013; Tsuji et al. 2013; Van den Brandt et al. 2020). The paired sphenethmoid forms a roughly hemi-cylindrical structure on the internal midline surface of the skull roof. On either side of the midline, each sphenethmoid plate is anteroposteriorly elongated and thin. The plates are solidly fused to the ventral surface of the frontals and the parietals. Each sphenethmoid plate curves ventromedially to meet at the midline, creating a cylindrical cavity which is longitudinally continuous with the brain cavity of the parabasisphenoid, indicating a long and narrow braincase. The ventral midline contact is wide, open and partially filled with matrix. In contrast, the midline suture of Embrithosaurus is fused, creating a ventrally projecting, sharp ridge.

The paired sphenethmoids narrow medially producing a 'dumbbell' shape as the anterolateral and posterolateral corners of the sphenethmoids extend laterally $15 \mathrm{~mm}$ beyond the narrowest point of the dumbbell. Anteriorly, the sphenethmoid has a large v-shaped notch, the result of damage to the bone as the undamaged holotype of Embrithosaurus has a triangular anterior projection at the anterior midline point and no notch. Posteriorly, beyond the hemi-cylindrical structure, the two sphenethmoid plates form narrow low ridges, and join the descending flange of the postparietal at the level of the parietal foramen.

3.3.2 Parabasisphenoid. As in all pareiasaurs, the braincase cavity (cavum cranii) is a median anteroposteriorly elongated cylindrical cavity, formed by the parabasisphenoid ventrally, prootic anterolaterally, opisthotic posterolaterally and supraoccipital dorsally. The parabasisphenoid sutures with the prootic anterodorsally, and the basioccipital posterodorsally and posteriorly (Fig. 8). The parabasisphenoid of SAM-PK-6238 extends anterolaterally to form the vertically oriented, teardrop, basipterygoid processes (Fig. 7), creating the posterior and posterolateral sides of the large interpterygoid vacuity.

The ventral surface of the parabasisphenoid forms the basal tubera (Figs 7,9). These are large anteroposteriorly elongated 
structures that diverge and widen posteriorly either side of a deep midline depression. SAM-PK-6238 shows that the posterolateral edges of the basal tubera are positioned closer to the posterior edge of the occipital condyle $(33 \mathrm{~mm})$ than to the narrowest part of the basipterygoid process $(64 \mathrm{~mm})$. This is the primitive pareiasaurian condition shared with Embrithosaurus, Bradysaurus baini and Bunostegos (Tsuji et al. 2013).

Posterior to the interpterygoid vacuity and the basipterygoid processes, the parabasisphenoid of Nochelesaurus is transversely constricted (SAM-PK-6238: $52 \mathrm{~mm}$ wide, SAM-PK-6239: 35 $\mathrm{mm}$ wide). The posterolateral edges of the basal tubera are much wider (SAM-PK-6238: 88 mm wide, SAM-PK-6239: 85 $\mathrm{mm}$ wide) producing an hourglass-shape when viewed ventrally.

Laterally, the parabasisphenoid has a short horizontal suture with the prootic which extends posteriorly to reach the anteroventral corner of the large, oval, posterodorsally oriented fenestra ovalis (Fig. 8a). The anterior border of this fenestra is curved and the posterior border is vertically straight. The parabasisphenoid forms the ventral border of the fenestra ovalis, the prootic forms the anterior, anterodorsal and dorsal borders, the opisthotic the posterior border and the basioccipital the posteroventral border. From the posteroventral corner of the fenestra ovalis a horizontal suture extends posteriorly to separate the parabasisphenoid from the basioccipital.

In dorsal view, the ventral floor of the cranial cavity is visible (Fig. 9b) where the holotype shows a large unidentified foramen, possibly the carotid foramen, just right of the midline.

Tubercles are present on the ventral surface of the basipterygoid process on either side of the interpterygoid vacuity (Fig. 7) but these tubercles are much smaller and less distinct than those of Scutosaurus (e.g., PIN 2005/1883).

3.3.3 Basiocciptal. The basioccipital is a medial bone located posteroventrally behind the cavum cranii and is almost indistinguishably fused with the parabasisphenoid. SAM-PK-6238 preserves the entire basioccipital, where the bone forms most of the large and round ( $68 \mathrm{~mm}$ wide, $63 \mathrm{~mm}$ high) occipital condyle, with the flattened dorsal surface made by the exoccipitals. The basioccipital forms the posterior edges of the basal tubera, which have pointed posterolateral ends (Figs 7, 9). In ventral view, the posterior and posteroventral surfaces of the basal tubera of the holotype (Fig. 9a) bear irregular grooves and ridges as in Bradysaurus baini and Embrithosaurus.

Laterally the horizontal sutural contacts of the basioccipital with the parabasisphenoid ventrally and the exoccipital dorsally are evident (Fig. 8). Posterior to the fenestra ovalis and on the same horizontal level, but more medially, is a large jugular foramen. Between the fenestra ovalis and the jugular foramen, the basioccipital shows a short horizontal suture with the dorsally positioned opisthotic (Fig. 8b). The jugular foramen is oval to circular and faces posteriorly with a very slight lateral inclination. The borders of the foramen are formed by the basioccipital ventrally and posteroventrally, the exoccipital posterodorsally, and the opisthotic anteriorly and anterodorsally. Between the fenestra ovalis and the jugular foramen is a posterodorsally oriented ridge that partially obscures the jugular foramen in lateral view (Fig. 8).

3.3.4 Exoccipital. The exoccipital is a paired element, positioned dorsal and lateral to the basioccipital (Fig. 9b), ventral to the supraoccipital and medial to the opisthotic and makes up the dorsolateral part of the occipital condyle. Above the condyle the exoccipital forms the ventral and lateral borders of the large, foramen magnum, which is slightly wider than high $(20 \mathrm{~mm}$ in transverse width). Best seen in dorsal view (Fig. 9b), the exoccipital extends laterally on either side of the foramen magnum as a thin, flat plate of bone, separated from the suparoccipital and the opisthotic by a deep transverse groove. The exoccipitals are separated dorsomedially by the supraoccipital (Fig. 9b). Medially the lateral flanges of the exoccipitals are positioned along the posterior edge of the parocciptal process of the opisthotic (Fig. 9b) and laterally they extend far, curving downwards to cover the posteroventral and ventral surface of the more distal portions of the paroccipital process of the opisthotic (CGP JA 109). In lateral view the exoccipital below the paroccipital process of the opisthotic, shows a long, anteriorly extending process that forms the posterodorsal border of the jugular foramen (Fig. 8a).

3.3.5 Supraoccipital. The supraoccipital is a single median bone, located posterodorsally on the braincase. It comprises a flat, horizontal, thin plate of bone forming the posterodorsal roof of the braincase and a thick, vertical, pillar of bone (the dorsal ascending process) that connects the braincase to the skull roof. The ascending process is diamond shaped in cross section and transversely wider than anteroposteriorly long. The supraoccipital forms the dorsal margin of the foramen magnum. A sharp, midline crista supraoccipitalis extends posteriorly on the dorsal surface of the supraoccipital (Fig. 9b).

3.3.6 Prootic. The prootic is a small curved element forming the anterior and anterodorsal parts of the lateral walls of the braincase cavity (Figs 8,9). The medial walls of the prootic that form part of the lateral walls of the braincase cavity are fully ossified. The indentation of the trigeminal nerve is present as a notch on the anterior margin of the prootic (Fig. 8b) and the prootic-parabasisphenoid suture runs posteriorly from below this indentation to the anteroventral corner of the fenestra ovalis. A small foramen, representing the exit of the facial nerve, is present above the prootic-parabasisphenoid suture, midway between the trigeminal indentation and the fenestra ovalis.

3.3.7 Opisthotic. The opisthotic is located on the posterolateral sides of the braincase and forms most of the paroccipital process that articulates the braincase with the skull roof. On the lateral wall of the braincase, the opisthotic is present between the prootic and the exoccipital. The opisthotic forms the posterior borders of the fenestra ovalis and behind this is a posterodorsally oriented sharp ridge (Fig. 8) on the anterior and anterodorsal borders of the jugular foramen.

The paroccipital process (holotype and CGP JA 109) is a transversely expanded, roughly horizontal, plate-like projection that emerges from the lateral sides of the braincase, immediately above the fenestra ovalis and the jugular foramen. In occipital view, the paroccipital process is u-shaped as in all basal South African pareiasaurs. Anteromedially, the process has a small anterior contribution formed by the prootic, above the fenestra ovalis (Fig. 8b). Laterally and posteriorly, the paroccipital process is formed by the opisthotics. The exoccipital flange covers the posterior edge of the paroccipital process of the opisthotic (Fig. 9b). Medially, at the dorsoventral level of the foramen magnum, the paroccipital process forms a horizontally flat and thin plate, extending laterally. It is dorsoventrally low and anteroposteriorly and mediolaterally expanded. The dorsal surface is concave and the ventral surface is convex. More laterally, this horizontal plate extends slightly downwards, having a deep elongated trough (Fig. 9b) as in Bradysaurus baini and Embrithosaurus. Lateral to the trough, the blade of the opisthotic curves and turns steeply upwards. The distal portion of the paroccipital process of the holotype is anteroposteriorly expanded $(55 \mathrm{~mm})$ similar to Embrithosaurus but much shorter than in B. baini. In Embrithosaurus and B. baini the posteromedial corner has a distinct posteriorly projecting, dorsomedially oriented, knob-like process (smaller in Embrithosaurus and larger in Bradysaurus baini). In Nochelesaurus, the posteromedial corner of the distal paroccipital process may be gently convex and swollen and there is no distinct dorsomedially oriented posterior process. In some Nochelesaurus specimens (e.g., CGP JA 109) the posteroventral edge of the distal paroccipital process as swollen and dorsolaterally oriented. 
On the inner skull roof, the distal end of the paroccipital process of the opisthotic sutures with the ventral process of the supratemporal and the medial process of the squamosal.

\subsection{Lower jaw}

SAM-PK-6238 preserves a an almost complete lower jaw (Figs 10,11) consisting of separated left and right rami with a small anteroventral section of the right ramus not preserved and plaster filling a large region of the left ramus. The holotype of Nochelesaurus has a partial right lower jaw (Figs 12, 13). CGP JA 109 preserves only partial posterior portions of both lower jaw rami, articulated to the quadrates.

The medial surface of the lower jaw is smooth but the lateral surface has a roughened mottled texture comprising numerous small bumps and shallow depressions. In dorsal view, the complete lower jaw of SAM-PK-6238 is broad and slightly pointed anteriorly and the posterior half of the rami curve slightly medially (Fig. 10). The dorsal half of the lower jaw, containing the teeth, is narrow and high, and the ventral half is mediolaterally wider and extends ventrolaterally.

Bone breaks on the lower jaw of the holotype and SAM-PK-6238 exposed overlapping sheet-like bones of the lower jaw in section. The dentary, splenial, coronoid and prearticular form most of the medial surface of the jaw, and the dentary and surangular most of the lateral. Severe dorsoventral compression affects the anterodorsal part of the holotype lower jaw such that the alveolar ridge and teeth are flattened and laterally displaced. The teeth are directed outwards (Fig. 13) instead of being vertically oriented and point outwards at about $20^{\circ}$ off the vertical. The undistorted and well preserved lower jaw of SAM-PK-6238 forms the basis of this description, with the holotype fragment used secondarily.

3.4.1 Dentary. The dentary forms most of the anterior two-thirds of the lower jaw and has greater exposure in lateral view than medially. A matrix-filled Meckelian canal extends dorsal to the splenial and coronoid (Figs 10a, 13). The dentary symphysis is fused into a vertical ridge. Internally, at the midline, the anteromedial portion of the dentary shows a narrow horizontal foramen intermandibularis medius (Lee 1994; Lee et al. 1997) which extends posteriorly into the Meckelian canal between the dentary and the splenial (Fig. 11).

The crista dentalis is situated medioventral of the tooth row as a horizontal shelf of bone on which four erupting replacement teeth are positioned in shallow depressions below the 1st, 3rd, 5 th and 10th teeth (Fig. 12). The shelf continues posteriorly to form the dorsal edge of the posterior dorsal 'fork' of the splenial. The right lateral side of SAM-PK-6238 has a long horizontal groove and a large foramen dentofaciale majus (Lee et al. 1997) below the 9th tooth (Fig. 11a).

3.4.2 Splenial. The splenial is an elongated bone on the medial side of the mandible that forms the ventral surface and most of the medial side of the lower jaw anterior to the angular, and laterally forms the ventrolateral edge of the jaw. Anteriorly, at the midline, the partially preserved left splenial of SAM-PK-6238 sutures vertically with its partner element and forms the ventral portion of the strongly ankylosed mandibular symphysis (Fig. 10). The midline ventral portion of the mandibular symphysis creates a significant mentum that projects posteroventrally and internally it forms a sharp, raised vertical ridge (Fig. 11).

Medially, the splenial has a long anterodorsal suture with the dentary. Anteriorly this suture starts below the shelf of the crista dentalis and rises posteriorly to merge with this shelf. Posteriorly, the splenial splits into two flanges (Fig. 11b), the dorsal one contacting the coronoid and the ventral one forming the anterior margin of the foramen intermandibularis caudalis. This foramen is large in the holotype (20 mm long, $15 \mathrm{~mm}$ high), and slightly smaller in SAM-PK-6238 (15 mm long, $12 \mathrm{~mm}$ high).

3.4.3 Angular. The angular is a mediolaterally narrow and anteroposteriorly elongated bone, with a dorsoventrally low main body. Posteriorly it forms most of the flat, ventral surface of the jaw (Fig. 10b). On the medial surface the angular forms the posteroventral border of the large foramen intermandibularis caudalis.

On the ventral surface of the lower jaw, the angular tapers anteriorly to a sharp point bounded laterally by the dentary and medially by the splenial (Fig. 10b). The ventral surface bears a horn-like ( $55 \mathrm{~mm}$ long) angular boss that points posteroventrally and slightly medially (Fig. 10b). As in Embrithosaurus, the angular boss of Nochelesaurus (SAM-PK-6238) is posteroventrally directed, with a slightly raised rim before the blunt distal tip. Bradysaurus baini has a similarly shaped, but relatively small angular boss, considering the large size of the skull.

Caudal to the angular boss, the angular becomes a flat horizontal bone with sharp lateral and medial edges (Fig. 10b), which continue on the articular. This is also a feature of Embrithosaurus. Anterior to the angular boss, the lateral and medial edges of the angular are more rounded and curved.

Both rami of SAM-PK-6238 have a vertically oriented shallow groove on the lateral surface of the angular, just below the intersection of the angular, surangular and dentary (Fig. 11a). This groove is also present in Embrithosaurus. Behind this groove, above the angular boss, the angular is swollen and bulges laterally.

3.4.4 Coronoid. The coronoid is a thin, flat, vertical and anteroposteriorly elongated bone positioned on the medial side of the lower jaw (Fig. 12). In medial view the coronoid has a long horizontal suture with the prearticular ventrally and anteriorly it has a short vertical suture with the splenial. Posterolaterally the vertical coronoid plate is almost completely overlapped by the dentary and the surangular.

Anteriorly the coronoid is at the same level as the alveolar ridge on the dentary, but posterior to the mandibular tooth row it extends dorsally to form the coronoid process (Fig. 11). Medially, the coronoid process forms the vertically oriented anterolateral and lateral rim of the adductor fossa, a depression positioned behind the tooth row on the dorsal and medial surface of the mandible (Fig. 11).

3.4.5 Prearticular. The prearticular is a flat sheet-like bone on the posteromedial side of the lower jaw, wedged between the two y-shaped flanges of the splenial (Figs 11, 12). Ventrally the prearticular forms a long, horizontal sutural contact with the angular which ends anteriorly at the foramen intermandibularis caudalis. Here the prearticular forms the posterodorsal margin of this large foramen. A prominent horizontal and slightly posteroventrally oriented shelf forms the floor of the adductor fossa (Fig. 11).

3.4.6 Surangular. The surangular covers most of the posterior half of the lateral surface of the lower jaw. It is a vertical slightly curved plate that forms an anterior tapering wedge between the dentary and the angular. Posteriorly it sutures with the articular with a curved vertical contact. SAM-PK-6238 has a deep elongated fossa (Fig. 11) on the posteroventral corner of the external surface of the surangular, but this fossa is absent in the holotype.

3.4.7 Articular. The articular is a robust and complex bone forming the posterior end of the lower jaw (Figs 10, 11). Anteriorly the articular narrows and extends into the intra-mandibular cavity. This anterior portion wedges between the plate-like surangular and prearticular. Posteriorly the articular widens and is triangular in dorsal view. The dorsal surface of the posterior portion of the angular is horizontally flat and forms the 
craniomandibular joint. The narrow and vertically deep intramandibular cavity opens dorsally (Fig. 10a). Its medial wall is formed by the prearticular and the lateral wall by the surangular, whereas the articular forms the posterior and posteromedial walls.

The medial and lateral articular cotyles are two shallow, concave depressions facing posterodorsally, and are at a level well below the tooth row. The medial cotyle $(35 \mathrm{~mm}$ wide, $47 \mathrm{~mm}$ long) is much larger than the lateral cotyle $(25 \mathrm{~mm}$ wide, 32 $\mathrm{mm}$ long), and has a transverse groove crossing its surface (Fig. 10a). The posteromedial corner of the medial cotyle extends medially as a flat, horizontal flange. The cotyles are separated by an anteroposteriorly oriented sharp ridge, and the anterior, lateral and posterior rim of each cotyle is thickened.

Behind the median longitudinal ridge that separates the cotyles, the posterior edge of the articular forms a large posterodorsally oriented retroarticular process (Fig. 10a) which projects posteriorly beyond the posterior edge of the cotyles. On the posteroventral edge of the articular, underneath the lateral cotyle, is a small, round protuberance ( $8 \mathrm{~mm}$ wide) which is visible in ventral (Fig. 10b) and lateral view (Fig. 11).

\subsection{Marginal dentition}

Most of the upper and lower teeth of the holotype of Nochelesaurus are poorly preserved and are broken midway between the crown base and apex. However, on the right upper margin, most of the crowns of the 3rd premaxillary and 1st and 2nd maxillary tooth are preserved (Fig. 14) and on the right lower jaw the 5 th and 6th teeth are well preserved (Fig. 15a).

The upper marginal teeth of SAM-PK-6238 are poorly preserved, with all crowns broken, except for the partially preserved 1st and 3rd left maxillary teeth. On the lower jaw, only the crowns of the right 10 th to $17 \mathrm{th}$ mandibular teeth are partially preserved (Fig. 15b). The complete lower jaw of SAM-PK-6238 indicates 19 mandibular teeth on each side. Sixteen mandibular teeth, representing most of the right lower jaw tooth row, are present (Fig. 13). Three premaxillary teeth, the largest teeth of the upper margin, are present either side of the midline in SAM-PK-6238. As in all other pareiasaurs both the upper and lower jaw teeth decrease in size posteriorly. The complete right maxilla of the holotype and SAM-PK-6238 each have 15 teeth and the left maxilla of SAM-PK-6238 (which is missing a small posterior section) has 14 . Thus, the upper margin of Nochelesaurus bears 18 teeth either side.

3.5.1 Upper marginal teeth. The upper marginal teeth of Nochelesaurus are higher than wide, labio-lingually flattened and leaf-shaped. They are similar to those of Bradysaurus baini and contrast with the wider upper marginal teeth of Embrithosaurus. The labial surface of the upper marginal teeth is convex and the lingual surface is slightly concave. The premaxillary and maxillary teeth of Nochelesaurus overlap each other such that in labial view, the mesial margin is partly covered by the distal margin of the adjacent tooth.

The upper marginal teeth have seven to eight cusps. The three central cusps are taller and placed very close together, forming a trident (Fig. 14). The trident is flanked by four smaller lateral cusps, two mesially and another two distally, with large gaps or spaces between the lateral cusps. The cusps located furthest from the trident are the smallest. The lowest of the mesial and distal marginal cusps are positioned $4 \mathrm{~mm}$ above the swollen base of the tooth. An additional very low and very small marginal cusp is present at the base of the mesial margin of the 2nd, 4th and 5th right maxillary teeth of the holotype (Fig. 14, cusp 1), resulting in eight cusps on some teeth, whereas the more common condition is seven. These unique very low and very small cusps create a non-symmetrical cusp arrangement. In stark contrast, Embrithosaurus and Bradysaurus baini present symmetrical marginal cusp arrangements on their maxillary teeth, making this asymmetry a unique feature of Nochelosaurus.

Three to five vertical ridges with shallow grooves are present on the lingual surfaces of the 3rd premaxillary and 1st right maxillary teeth of the holotype (Fig. 14). These ridges extend down from the three cusps at the apex (when central three ridges are present) or otherwise from the first lateral cusps either side of the central trident (when five ridges are present).

3.5.2 Lower teeth. In the Nochelesaurus holotype and SAM-PK-6238 the lower teeth are dorsoventrally elongated, similar to the shape of the dentary teeth in Bradysaurus baini and very different from the shorter and wider shape of Embrithosaurus. Lower and upper marginal teeth of Nochelesaurus are identical except for the presence of an incipient lingual cingulum on certain lower teeth (sometimes bearing cusps) and the number of marginal cusps.

The number of marginal cusps varies from seven to ten. On the holotype, the 5th right tooth has at least eight cusps and the 6th has ten (Fig. 15a). SAM-PK-6238 has seven to eight and possibly more cusps (Fig. 15b). This variability is due to the variable presence of (1) an extra very low and small cusp at the base of the mesial margin, as on the upper marginal teeth (Fig. 15a, b, cusps 1); and (2) one or two extra very small, vertically pointed cusps on the cingulum (Fig. 15a, cusps 9,10). The small vertical cusps are positioned on an incipient horizontal cingulum ridge, present on certain lower teeth of the holotype (the 5th and 6th right teeth) and SAM-PK-6238 (12th right tooth) and are unique to Nochelesaurus. The extra very low and small cusp at the base of the mesial margin creates a non-symmetrical cusp arrangement (as in the upper marginal teeth) and are visible only on well-preserved teeth, which suggests their absence is a preservation bias. These extra marginal basal cusps are absent in other mid-Permian pareiasaurs, except for one specimen of Bradysaurus (NHMUK PV OR49426) which has an extra distal marginal cusp on its lower teeth.

Three vertical ridges, separated by deep grooves, are present lingually on the holotype (Fig. 15a). Three undeveloped, erupting replacement teeth, located below the 1st, 3rd and 5th teeth also show three vertical ridges. SAM-PK-6238 has only one distinct vertical ridge on the 11th, 14th and 16th right teeth (Fig. 15b). A specimen of Bradysaurus (NHMUK PV OR49426) has three high distinct vertical ridges. Only Embrithosaurus lacks a distinct lingual vertical ridge and instead has a smooth, low, horizontally triangular bulge at the base of the lingual surface of each mandibular tooth (Van den Brandt et al. 2020).

\section{Discussion}

Supporting the validity of Nochelesaurus, our study shows new dental features, distinctive cranial ornamentation, and distinctive shapes of the postparietal and paroccipital process. However, there is much overlap of features between Nochelesaurus and the other mid-Permian pareiasaurs in certain shared dental features and the shape of the postfrontal. Additionally, some pareiasaurian features are not very useful for species separation.

\subsection{New dental features of Nochelesaurus}

Nochelesaurus has a very low cusp at the base of the mesial margin of lower jaw teeth, which creates a non-symmetrical cusp arrangement. Embrithosaurus and most specimens of Bradysaurus present symmetrical cusp arrangements on lower teeth, making non-symmetrical cusp arrangements useful for taxonomic and species identification purposes of Nochelesaurus. Only one specimen of Bradysaurus (NHMUK PV OR49426) has a very low basal cusp, but this is on the distal margin. 
Another important finding for Nochelesaurus is the presence of an incipient horizontal lingual cingulum ridge, sometimes bearing small medially positioned cusps on the lower teeth. We have also identified these lingual medial (not marginal) cusps in a few specimens of Bradysaurus (SAM-PK-K11638, NHMUK PV OR49426), but the incipient lower cingulum occurs only in Nochelesaurus (SAM-PK-6239, SAM-PK6238). The presence of a lingual cingulum is currently considered a derived character and is present in several of the late Permian forms (Turner et al. 2015, characters 72 and 73) but among mid-Permian taxa this is present only in Nochelesaurus.

Nochelesaurus and some specimens of Bradysaurus (NHMUK PV OR49426) have one to three vertical ridges on the lingual surface of the mandibular teeth and Embrithosaurus has a smooth wide bulge instead. The presence of lingual vertical ridges on mandibular teeth is considered a derived character (Turner et al. 2015, character 71).

\subsection{Distinctive cranial ornamentation of Nochelesaurus}

Pareiasaurian cranial ornamentation (size and shape of the bosses, ridges, grooves and pits) and sculpturing patterns varies significantly between taxa. Where species specific cranial ornamentation exists, it has been used by most authors to distinguish between taxa. For example Pareiasaurus serridens is diagnosed as having a reticulated network of uniform fine raised ridges and small pits, and lacking central bosses on each element (Lee 1994, 1997a). Deltavjatia has distinctive subcircular, 'lozengeshaped' bosses that produce a 'pustule-like' pattern on the skull roof and flat areas with radiating depressed grooves emanating from central bosses (Tsuji 2013). Lee (1994, 1997a) distinguishes Anthodon as being covered by a network of shallow, smooth pits, widely spaced and with no raised bosses or ridges.

We agree with Lee $(1994,1997 \mathrm{a})$ in recognising the more distinctive bosses on the posterior margins of the cheeks of Nochelesaurus as an important distinguishing feature amongst the co-occurring South African pareiasaurs. Lee also maintained that all large mid-Permian South African pareiasaurs have the same general cranial sculpturing style and pattern consisting of low, rounded bosses in the centre of each bone, with regular, low, ridges radiating. Nochelesaurus is distinctive in that it has cranial bosses, including the corner cheek boss (see below), that are generally higher, longer, more conical and more pointed, especially on the posterior edge of the cheek. Nochelesaurus also features a more distinct and larger central boss of the frontal, more distinctive bosses on the lateral surface of the quadratojugal, a larger boss on the posterolateral edge of the squamosal, and more distinct orbital marginal bosses of the prefrontal, postfrontal and postorbital. The lack of a maxillary boss in Nochelesaurus adds to the distinctive cranial ornamentation.

The distinct large, midline boss at the nasal-frontal contact present on the holotype of Nochelesaurus alexanderi is not present in referred specimens or any other mid-Permian pareiasaurs. It may be ascribed to a display feature resulting from sexual dimorphism, intraspecific variability or a pathology.

The morphology of the corner cheek boss on the quadratojugal has been considered diagnostic in different species. In Deltavjatia this boss is long, flattened and rectangular in adults (Lee 1994, 1997a; Tsuji 2010, 2013). Provelosaurus americanus has two prominent cylindrical bosses instead (Cisneros et al. 2005). In Elginia (Newton 1893), Arganaceras (Jalil \& Janvier 2005) and Scutosaurus (Lee 1994) the corner boss is very long, pointed and horn-shaped, and in Obirkovia it is conical (Bulanov \& Yashina 2005). The shape of the corner boss in Nochelesaurus can be used to differentiate it from Bradysaurus baini and Embrithosaurus schwarzi as it is larger, much longer than wide, more prominent, sometimes covered by rugosities and may present a long, thin neck, followed by a raised distal rim. We interpret the more distinctive cranial ornamentation of Nochelesaurus as a clear indication of a separate species from the co-occurring pareiasaurs.

\subsection{Distinctive postparietal of Nochelesaurus}

Late Permian pareiasaurs appear to have narrow postparietals flanked by supernumerary bones. Mid-Permian pareiasaurs lack supernumerary bones and exhibit two distinct morphologies of the postparietal: (1) a narrow postparietal in Bradysaurus and Embrithosaurus, and (2) a wide postparietal in Nochelesaurus. Van den Brandt et al. (2020) confirmed a narrow postparietal on the holotype skull of Embrithosaurus schwarzi (contra to Boonstra 1934) and the most secure confirmation of a narrow postparietal in Bradysaurus baini we observed in the juvenile specimen CGP/1/2269. The holotype of Nochelesaurus and specimen SAM-PK-6238 show obvious sutures confirming wide postparietals, a condition that appears to be autapomorphic as it is absent in all other pareiasaurs.

\subsection{Distinctive distal paroccipital process of the opisthotic of Nochelesaurus}

One of the three cranial autapomorphies of Bradysaurus baini put forward by Lee (1997a: 247) is that of a 'greatly swollen' distal paroccipital process of the opisthotic. Van den Brandt et al. (2020) considered Lee's autapomorphy to comprise two features: (1) an anteroposterior expansion, and (2) a dorsomedially elongated, oblique, posteriorly projecting knob-like process on the medial edge of the posterodorsal corner of the paroccipital process. Regarding the first point, Van den Brandt et al. (2020) noted a similar anteroposterior expansion in Embrithosaurus and Nochelesaurus but it is much larger in B. baini. In relation to the second feature, Van den Brandt et al. (2020) noted the dorsomedial posterior process as absent in Nochelesaurus and present in both Embrithosaurus and B. baini (larger in B. baini).

This study confirms that in Nochelesaurus, (1) there is no dorsomedially elongated posterior process at the medial edge of the posterodorsal corner of the distal paroccipital process, well above the posteroventral edge of the paroccipital process, but this region may be gentle convexly swollen, and (2) sometimes the posteroventral edge of the distal paroccipital process is swollen to form a low, dorsolateral elongation.

\subsection{Shared dental features}

Embrithosaurus is no longer the only mid-Permian South African pareiasaur to have teeth with more than seven cusps (contra Broom 1935; Lee 1994, 1997a; Van den Brandt et al. 2020). This is because several specimens have more than seven cusps on the maxillary and mandibular teeth: Nochelesaurus alexanderi (SAM-PK-6239: seven to eight cusps, upper marginal teeth, eight to ten cusps, lower teeth; SAM-PK-6238: seven to eight cusps, lower teeth; FMNH UR 2755: nine cusps, lower teeth); and Bradysaurus baini (NHMUK PV OR49426: seven to eight cusps, upper and lower teeth; SAM-PK-K11638: eight to nine cusps, upper and lower teeth; BP/1/7082: nine cusps, upper marginal teeth). The presence of a greater number of cusps is phylogenetically important as the number of cusps is higher in more derived taxa (Lee 1994, 1997a; Turner et al. 2015, characters 69 and 70) and numbers nine or more in all late Permian pareiasaurs, apart from Bunostegos. The mid-Permian South African pareiasaurs however have the lowest number of cusps, and as few as seven cusps occur in all three genera. It is clear that the dentition of Nochelesaurus is more similar to that of Bradysaurus than Embrithosaurus. 


\subsection{Shared postfrontal shape}

Nochelesaurus and Bradysaurus have large, square postfrontals, whereas the postfrontal of Embrithosaurus are small and mediolaterally elongated. The postfrontal is the only skull roof element to exhibit different shapes and sizes when viewed dorsally and ventrally. This has caused historic confusion and disagreement. Watson (1914) using internal sutures only, illustrated a very small, mediolaterally elongated postfrontal in Embrithosaurus schwarzi (NHMUK PV R7782).

Broom (1924) noted the postfrontal as large and roughly square (as large as the prefrontal) in a juvenile specimen of a large pareiasaur, hypothesising that this specimen is either a different species to Watson's (1914) specimen or that the large postfrontal bone may appear smaller when viewed internally as done by Watson. Broom's (1924) unnumbered juvenile skull, now untraceable and lost, seems to have been a specimen of Bradysaurus baini as it has a narrow postparietal and a large, roughly square postfrontal. These two features agree with our study of CGP/1/2269 which we identified as a juvenile B. baini because of its medially inflicted upper marginal teeth.

Boonstra (1934), based on both internal and external sutures, noted the postfrontal to be much larger than the way it was figured by Watson (1914), describing the bone as longitudinally elongated in most if not all pareiasaurs.

Lee (1995) declared that all pareiasaurs possess relatively small, mediolaterally elongated postfrontals that show a feeble contribution to the orbital margin and designed a phylogenetic character around this point to separate pareiasaurs from outgroups (Lee 1995, character 25). In our cranial description of Embrithosaurus (Van den Brandt et al. 2020) we discussed the contrasting shape of the postfrontal when viewed internally (mediolaterally elongated and small) compared to externally (longitudinally elongated and large), and defined the shape of this bone after the more clearly exposed internal sutures. Our studies thus show that the postfrontal internal morphology is mediolaterally elongated in Embrithosaurus schwarzi and square to slightly longitudinally elongated in Nochelesaurus alexanderi and Bradysaurus baini.

\subsection{Features less useful for species identification}

Haughton \& Boonstra (1930) produced a detailed study of the pareiasaurian mandible, noting the difficulty of using the morphology of the mandible for reliable species identification, and that specimens of the same genus may have very dissimilar mandibles and conversely that very dissimilar skulls have similar mandibles. Our research confirms huge variability and lack of consistent lower jaw morphology in specimens of the same species (e.g., Embrithosaurus specimen NHMUK PV R7782 has a massively oversized lower jaw with the greatest dorsoventral extent observed). Tsuji (2010) showed that the size and shape of the pareiasaurian angular boss changes during ontogeny in Deltavjatia, demonstrating that the size and shape of the angular boss cannot be used for taxonomic purposes. As the morphology of the angular boss is highly variable in mid-Permian pareiasaurian species we caution against using the morphology of the angular boss in species identification. However, the size of the angular boss is larger in most specimens of Embrithosaurus and Nochelesaurus, and generally smaller in specimens of Bradysaurus (including very large Bradysaurus skulls).

\section{Conclusion}

Nochelesaurus alexanderi has never been properly described before, the existing description is nearly 100 years old (Haughton \& Boonstra 1929) and this study has produced the first detailed cranial description. The morphology of the individual cranial elements have been determined accurately for the first time and the cranial features have been described in detail to allow for more accurate comparison with the co-occurring pareiasaurian species. Nochelesaurus alexanderi is a distinct taxon based on the presence of one autapomorphy, a transversely wide postparietal, distinctive bosses on the posterior edge of the cheek flange (quadratojugal and squamosal) and the orbital rim (prefrontal, postfrontal and postorbital), no maxillary boss, no posterior process on the distal paroccipital process of the opisthotic, large cheek flanges and a narrow maxilla with downwards pointing upper marginal teeth. Diagnostic traits that were newly identified in this study include the wide postparietal and several dental features: non-symmetrical marginal cusp arrangements on upper and lower teeth created by an extra basal mesial cusp; an incipient horizontal cingulum on lower jaw teeth, sometimes with one or two tiny medial cingular cusps; and up to ten marginal cusps.

We confirm Lee $(1994,1997 a)$ synonymy of Dolichopareia angusta (Haughton \& Boonstra 1929) with Nochelesaurus alexanderi and in this study have made extensive use of the holotype, SAM-PK-6238. SAM-PK-6238 has vertical upper marginal teeth, no maxillary boss, a roughly square longitudinally elongated postfrontal, a rectangular and wide postparietal, and mandibular teeth with an incipient cingulum ridge and a low basal mesial cusp. The low and indistinct bosses on the posterior border of the cheeks are the result of severe weathering and over-preparation.

The next stage in this our research project is to study the postcranial features of all valid species of mid-Permian South African pareiasaurs. This updated Nochelesaurus cranial description and analysis has resulted in changes to the character scores of several dozen cranial characters for Nochelesaurus, Embrithosaurus and Bradysaurus, and an updated phylogenetic analysis will be presented later, when we present our final taxonomic conclusions, diagnoses and stratigraphic ranges of all valid mid-Permian South African species at the conclusion of this project.

\section{Acknowledgements}

Michael Lee, Michael Benton, Nour-Eddine Jalil, Juan Carlos Cisneros, Andrey Sennikov, Elena Boyarinova, Sean Modesto and Linda Tsuji are sincerely thanked for generously sharing their knowledge and pareiasaurian discussions. For access to the material studied, we thank Ellen de Kock, Johann Neveling and Nonhlanhla Mchunu (CGP); Bernhard Zipfel and Sifelani Jirah (ESI); William Simpson and Kenneth Angielczyk (FMNH); Sandra Chapman, Mike Day and Paul Barrett (NHMUK); V. V Bulanov, Valeriy Golubev and Andrey Sennikov (PIN); Zaituna Skosan, Sibusiso Mtungata and Roger Smith (SAM) and Tom White (UMZC). For additional cranial preparation of the holotype Nochelesaurus alexanderi (SAM-PK-6239), we thank Gilbert Mokgethoa and Charlton Dube (ESI) and for specimen SAM-PK-6238 we thank Johann van den Berg (SAM). The research trip to the Paleontological Institute of the Russian Academy of Sciences, Moscow (PIN) was made possible through the support of the Bi-national Cooperation project between South Africa (NRF to Fernando Abdala) and Russia (Russian Foundation for Basic Research to Andrey Sennikov). We acknowledge the financial support provided by the Department of Science and Innovation and the National Research Foundation (DSI/NRF) Centre of Excellence in Palaeosciences (CoE-Pal), South Africa; the National Research Foundation (NRF), South Africa; the Paleontological Scientific Trust (PAST) and its Scatterlings of Africa program; Johannesburg, South Africa; the African Origins Program (AOP) of the National Research Foundation (NRF), South Africa, under Bruce Rubidge and the University of the 
Witwatersrand, Johannesburg, South Africa. Fernando Abdala's research is financed by the NRF of South Africa and Conicet from Argentina. The support of the DST/NRF Centre of Excellence in Palaeosciences (CoE-Pal) towards this research is hereby acknowledged. Opinions expressed and conclusions arrived at, are those of the author and are not necessarily to be attributed to the $\mathrm{CoE}$.

\section{References}

Benton, M. J. 2016. The Chinese pareiasaurs. Zoological Journal of the Linnean Society 177, 813-53.

Boonstra, L. D. 1932. The phylogenesis of the Pareiasauridae: a study in evolution. South African Journal of Science 29, 480-6.

Boonstra, L. D. 1934. Pareiasaurian studies. Part 9. The cranial osteology. Annals of the South African Museum 31, 1-38.

Boonstra, L. D. 1969. The fauna of the Tapinocephalus Zone (Beaufort beds of the Karoo). Annals of the South African Museum 56, 1-73.

Broom, R. 1903. On an almost perfect skeleton of Pareiasaurus serridens Owen. Annals of the South African Museum 4, 123-38.

Broom, R. 1924. On some points in the structure of the Pareiasaurian skull. Proceedings of the Zoological Society of London 1924, 499-508.

Broom, R. 1935. Notes on some species of pareiasaurian reptiles. Annals of the Transvaal Museum 18, 37-51.

Bulanov, V. V. \& Yashina, O. V. 2005. Elginiid pareiasaurs of Eastern Europe. Palaeontological Journal 39, 428-32.

Cisneros, J. C., Abdala, F. \& Malabarba, M. C. 2005. Pareiasaurids from the Rio do Rasto formation, southern Brazil: biostratigraphic implications for Permian faunas of the Parana basin. Revista Brasileira de Paleontologia 8, 13-24.

Cope, E. D. 1896. The reptilian order Cotylosauria. Proceedings of the American Philosophical Society 34, 436-56.

Damiani, R. \& Modesto, S. P. 2001. The morphology of the pareiasaurian vomer. Neues Jahrbuch für Geologie und Paläontologie, Monatshefte 2001, 423-34.

Day, M. O., Ramezani, J., Bowring, S. A., Sadler, P. M., Erwin, D. H., Abdala, F. \& Rubidge, B. S. 2015. When and how did the terrestrial mid-Permian mass extinction occur? Evidence from the tetrapod record of the Karoo Basin, South Africa. Proceedings of the Royal Society of London B 282, 20150834.

Haughton, S. H. \& Boonstra, L. D. 1929. Pareiasaurian studies. Part I. An attempt at a classification of the Pareiasauria based on skull features. Annals of the South African Museum 28, 79-87.

Haughton, S. H. \& Boonstra, L. D. 1930. Pareiasaurian studies. Part 5. On the pareiasaurian mandible. Annals of the South African Museum 28, 261-88.

Jalil, N.-E. \& Janvier, P. 2005. Les pareiasaures (Amniota, Parareptilia) du Permien superieur du Bassin d'Argana, Maroc. Geodiversitas 27, 35-132.

Kitching, J. W. 1995. Biostratigraphy of the Dicynodon Assemblage Zone. In: Rubidge, B. S. (ed.). Biostratigraphy of the Beaufort Group (Karoo Supergroup), Biostratigraphic Series 1. South African Committee for Stratigraphy, Pretoria, 29-34.

Kuhn, O. 1969. Cotylosaria. Handbuch der palaoherpetologie, Teil 6. Stuttgart: Gustav Fischer Verlag.

Laurenti, J. N. 1768. Classis Reptilium. Specimen medicum, exhibens synopsis Reptilium emendatum, cum experimentis circa venena et antidote Reptilium Austriacorum. J. Thom., Nob. et Trattnern, Vienna.

Laurin, M. \& Reisz, R. R. 1995. A reevaluation of early amniote phylogeny. Zoological Journal of the Linnean Society 113, 165-223.

Lee, M. S. Y. 1993. The origin of the turtle body plan: bridging a famous morphological gap. Science (New York, N. Y.) 261, 1716-20.
Lee, M. S. Y. 1994. Evolutionary morphology of pareiasaurs. Unpublished $\mathrm{PhD}$ thesis, University of Cambridge, Cambridge, 1-392.

Lee, M. S. Y. 1995. Historical burden in systematics and the interrelationships of 'parareptiles'. Biological Reviews 70, 459-547.

Lee, M. S. Y. 1997a. A taxonomic revision of pareiasaurian reptiles: implications for Permian terrestrial palaeoecology. Modern Geology 21, 231-98.

Lee, M. S. Y. 1997b. Pareiasaur phylogeny and the origin of turtles. Zoological Journal of the Linnean Society 120, 197-280.

Lee, M. S. Y., Gow, C. E. \& Kitching, J. W. 1997. Anatomy and the relationships of the pareiasaur Pareiasuchus Nasicornis from the upper Permian of Zambia. Palaeontology 40, 307-35.

Liu, J. \& Bever, G. S. 2018. The tetrapod fauna of the upper Permian Naobaogou Formation of China: a new species of Elginia (Parareptilia, Pareiasauria). Papers in Palaeontology 4, 197-209. https://doi. org/10.1002/spp2.1105

Newton, E. T. 1893. On some new reptiles from the Elgin sandstones. Philosophical Transactions of the Royal Society of London B 184, 431-503.

Olson, E. C. 1947. The Family Diadectidae and its bearing on the classification of reptiles. Fieldiana Geology 11, 1-53.

Seeley, H. G. 1888. Researches on the structure, organisation, and classification of the fossil Reptilia. II. On Pareiasaurus bombidens (Owen), and the significance of its affinities to amphibians, reptiles and mammals. Philosophical Transactions of the Royal Society of London B 179, 59-109.

Seeley, H. G. 1892. Researches on the structure, organisation, and classification of the fossil Reptilia. VII. Further observations on Pareiasaurus. Philosophical Transactions of the Royal Society of London B 183, 311-70.

Smith, R. M. H. \& Keyser, A. W. 1995a. Biostratigraphy of the Tapinocephalus Assemblage Zone. In: Rubidge, B. S. (ed.) Biostratigraphy of the Beaufort Group (Karoo Supergroup), Biostratigraphic Series 1. South African Committee for Stratigraphy, Pretoria, 8-12.

Smith, R. M. H. \& Keyser, A. W. 1995b. Biostratigraphy of the Tropidostoma Assemblage Zone. In: Rubidge, B. S. (ed.) Biostratigraphy of the Beaufort Group (Karoo Supergroup), Biostratigraphic Series 1. South African Committee for Stratigraphy, Pretoria, 18-22.

Smith, R. M. H. \& Keyser, A. W. 1995c. Biostratigraphy of the Cistecephalus Assemblage Zone. In: Rubidge, B. S. (ed.) Biostratigraphy of the Beaufort Group (Karoo Supergroup), Biostratigraphic Series 1. South African Committee for Stratigraphy, Pretoria, 23-28.

Tsuji, L. A. 2010. Evolution, morphology and paleobiology of the pareiasauria and their relatives (Amniota: Parareptilia). Unpublished $\mathrm{PhD}$ thesis, Humboldt-University of Berlin, Berlin, $188 \mathrm{pp}$.

Tsuji, L. A. 2013. Anatomy, cranial ontogeny and phylogenetic relationships of the pareiasaur Deltavjatia rossicus from the Late Permian of central Russia. Earth and Environmental Science Transactions of the Royal Society of Edinburgh 104, 1-42.

Tsuji, L. A., Sidor, C. A., Sebastien Steyer, J., Smith, R. M. H., Tabor, N. J. \& Ide, O. 2013. The vertebrate fauna of the Upper Permian of Niger-VII. Cranial anatomy and relationships of Bunostegos akokanenis (Pareiasauria). Journal of Vertebrate Palaeontology 33 747-63.

Turner, M. L., Tsuji, L. A., Ide, O. \& Sidor, C. A. 2015. The vertebrate fauna of the Upper Permian of Niger -IX. The appendicular skeleton of Bunostegos akokanenis (Parareptilia: Pareiasauria). Journal of Vertebrate Palaeontology 35, e994746.

Van den Brandt, M. J., Abdala, F. \& Rubidge, B. S. 2020. Cranial morphology and phylogenetic relationships of the middle Permian pareiasaur Embrithosaurus schwarzi from the Karoo Basin of South Africa. Zoological Journal of the Linnean Society 188, 202-41.

Watson, D. M. S. 1914. On the skull of a pareiasarian (sic) reptile, and on the relationships of that type. Proceedings of the Zoological Society of London 1914, 155-80.

MS received 10 June 2020. Accepted for publication 13 January 2021. First published online 5 March 2021 